\title{
New Modeling of AgFeNi2S4-Graphene-TiO2 \\ Ternary Nanocomposite Synthesized Via the Pechini Method for the Enhanced Electrophotocatalytic Reduction of $\mathrm{CO} 2$
}

\author{
Zambaga Otgonbayar \\ Hanseo University \\ Won-Chun Oh ( $\nabla$ wc_oh@hanseo.ac.kr) \\ Hanseo University https://orcid.org/0000-0002-0154-7388
}

\section{Research Article}

Keywords: Quaternary semiconductor, Graphene, Ternary nanocomposite, Photoreduction of CO2, electrochemical reduction of $\mathrm{CO} 2$, Faraday efficiency

Posted Date: June 16th, 2021

DOl: https://doi.org/10.21203/rs.3.rs-612368/v1

License: (c) (1) This work is licensed under a Creative Commons Attribution 4.0 International License.

Read Full License 


\title{
New Modeling of $\mathrm{AgFeNi}_{2} \mathrm{~S}_{4}-\mathrm{Graphene}^{-\mathrm{TiO}_{2}}$ Ternary Nanocomposite synthesized via the Pechini Method for the Enhanced Electrophotocatalytic Reduction of $\mathrm{CO}_{2}$
}

\author{
Zambaga Otgonbayar ${ }^{1}$, Won-Chun Oh $^{1.2 *}$ \\ ${ }^{1}$ Department of Advanced Materials Science \& Engineering, Hanseo University, Seosan-si, Chungnam, \\ Korea, 356-706 \\ ${ }^{2}$ Anhui International Joint Research Center for Nano Carbon-based Materials and Environmental \\ Health, College of Materials Science and Engineering, Anhui University of Science \& Technology,
} Huainan 232001, PR China

\begin{abstract}
For reduction of $\mathrm{CO}_{2}$ into hydrocarbon fuels, an $\mathrm{AgFeNi} 2 \mathrm{~S}_{4}-\mathrm{Graphene}^{-\mathrm{TiO}_{2}}$ ternary nanocomposite material was synthesized via the Pechini method. The Pechini method is based on a chelating agent which, together with ethylene glycol $\left(\mathrm{C}_{2} \mathrm{H}_{6} \mathrm{O}_{2}\right)$ and citric acid $\left(\mathrm{C}_{6} \mathrm{H}_{8} \mathrm{O}_{7}\right)$ as a chelating cation, can affect the structure and stability of the nanocomposite. The catalytic activity of the photocatalyst for photocatalytic and electrochemical $\mathrm{CO}_{2}$ evolution into hydrocarbon fuels was tested. The methanol yield under UV light was $8.679 \%, 6.349 \%$, and $4.136 \%$, and the methanol yields under visible light was $6.291 \%, 4.738 \%$, and $2.339 \%$, respectively. The stability and reusability of the photocatalyst remained high after a 4-cycle recycling test without a decrease in yield of the final photocatalytic $\mathrm{CO}_{2}$ reduction product. The enhanced photoreduction of $\mathrm{CO}_{2}$ through the as-prepared ternary photocatalyst can be ascribed to the catalyst's conformation and low recombination rate. In electrochemical $\mathrm{CO}_{2}$ reduction, the Faraday efficiency is the main parameter that defines the performance of the working electrode and the evolution of methanol. The Faraday efficiency of AFNSGT ternary nanocomposite was $44.25 \%$; this is an increase in the value of the Faraday efficiency, which proves that the design of the new nanocomposite successfully increases the activity of the working electrode and has a positive effect on the electrochemical reduction of $\mathrm{CO}_{2}$. The photocatalytic and electrochemical $\mathrm{CO}_{2}$ reduction data show that the preparation method, morphological state, and charge carrier properties of the photocatalyst are important for the catalytic activity and efficiency of the methanol evolution
\end{abstract}

\footnotetext{
*Corresponding author

E-mail: wc_oh@hanseo.ac.kr

Tel: +82-41-660-1337, Fax: +82-41-688-3352
} 
pathway. This study provides a strategy for fabrication of a new ternary nanocomposite based on 2D-structured graphene, $\mathrm{TiO}_{2}$, and a quaternary nanocomposite.

Keywords. Quaternary semiconductor, Graphene, Ternary nanocomposite, Photoreduction of $\mathrm{CO}_{2}$, electrochemical reduction of $\mathrm{CO}_{2}$, Faraday efficiency

\section{Introduction}

Industrial development is increasing both the use of fossil fuels and the amount of carbon dioxide and air pollution [1-5]. The simplest and most commonly used solution to these problems is a photocatalyst-based process. Crystal structure, nanoparticle size, band structure, and charge transfer are the main parameters that determine the catalytic activity of a photocatalyst, and these values vary depending on the synthetic method [6-8]. Many different methods are used to synthesize photocatalysts, such as the sol-gel, hydrothermal, combustion and ultrasonic-assisted methods [9-15]. Among them, the Pechini method, which is a type of modified sol-gel method, allows control of the particle size and stoichiometry. The basic process is chelation based on alpha-hydroxide carboxylic acid and organic solvents to form a metal chain by creating chemical interactions between metals and organic molecules [16]. The transition metal chalcogenide is mainly used in the catalytic research field because it has unique properties. Nickel sulfide serves as a good co-catalyst, as it has low Fermi-level energy which can capture the photo-generated electron and push the reduction reaction on the catalyst [17-20]. Quaternary nanocomposites are attracting the attention of researchers, and it is possible to synthesize quaternary nanocomposites with semi-insulating properties and high catalytic activity by combining nickel sulfide with transition metals using appropriate synthetic methods.

In addition, $2 \mathrm{D}$ graphene and titanium oxide $\left(\mathrm{TiO}_{2}\right)$ photocatalysts are widely studied in photocatalytic $\mathrm{CO}_{2}$ reduction due to their physical and chemical properties. Graphene acts as a better catalyst than $0 \mathrm{D}$ and 1D nanomaterials and has a high surface area and high charge transfer capacity [21-23]. $\mathrm{TiO}_{2}$ offers a strong oxidizing ability and good physical stability, but this semiconductor material can become activated in the UV region $(<387 \mathrm{~nm})$ and is subject to rapid convergence of electrons and holes due to its band gap energy (3.20 eV) [24]. Previous studies have shown that the graphene- $\mathrm{TiO}_{2}$ binary photocatalyst material showed high conversion efficiency for $\mathrm{CO}_{2}$ under light irradiation. Graphene can strengthen the physical and chemical stability of the metal-junctioned binary material [25]. Recently, novel structured ternary photocatalysts have shown advantages over binary catalysts because of their strong light absorption rate and enhanced photocatalytic potency. The combination of two or more 
semiconductors has many advantages, such as band structure, energy adjustment, efficient charge transport, and high catalyst activity; these properties have allowed nanomaterials to find a range of new applications [26, 27].

Based on the above mentioned superiority, our research proposes a new method of modeling a ternary nanocomposite based on graphene, $\mathrm{TiO}_{2}$, and a quaternary semiconductor. 2D-structured graphene increases not only the surface area but also the light absorption capacity and can act as a bridge between semiconductors to enhance the degree of photogenerated charge transfer. The catalytic activity of the newly modeled ternary nanocomposite was evaluated based on the conversion of $\mathrm{CO}_{2}$ to hydrocarbon fuel under light radiation using an electron donor scavenger. Various methods have been used for $\mathrm{CO}_{2}$ reduction, such as photocatalytic, electrochemical, and photo-electrochemical techniques. Among them, the electrochemical and photocatalytic reduction of $\mathrm{CO}_{2}$ to value-added products has been shown to be effective due to its simplicity and ability to operate under ambient circumstances [28]. The carbon dioxide conversion rate depends on several fundamental factors, such as the surface and morphology of the nanocomposite, composition and experimental conditions. The electron-donor purifier can provide a sufficient number of cycle electrons and allow $\mathrm{CO}_{2}$ to combine with water, thus improving the $\mathrm{CO}_{2}$ conversion process and supporting the catalytic activity of the photocatalyst [29].

Herein, we prepared an $\mathrm{AgFeNi}_{2} \mathrm{~S}_{4}-\mathrm{Graphene}^{-\mathrm{TiO}_{2}}$ ternary nanocomposite material synthesized via the Pechini method. The final ternary photocatalyst demonstrated the ability to efficiently separate and transfer charges due to the synergistic effects of the new design. Also, the good electrical conductivity of graphene provides semiconductor conduction and the 2D structure provides charge transfer fields. The $\mathrm{CO}_{2}$ conversion efficiency of the ternary photocatalyst was greater than that of unary and binary catalysts in the photocatalytic and electrochemical reduction process. Sufficient electron-donor reagents were used to improve the performance of the photocatalyst, and the experimental results showed that the final methanol content was relatively high. Our work demonstrates a new technique to assemble a graphene-based catalyst with systematized $\mathrm{CO}_{2}$ reduction activity.

\section{Experimental}

\subsection{Materials}

$\mathrm{AgNO}_{3}(\geq 98 \%), \mathrm{Fe}\left(\mathrm{NO}_{3}\right)_{3} \cdot 9 \mathrm{H}_{2} \mathrm{O}(99.9 \%), \mathrm{Ni}\left(\mathrm{NO}_{3}\right)_{2} \cdot 6 \mathrm{H}_{2} \mathrm{O}(\geq 99 \%), \mathrm{Na}_{2} \mathrm{~S}_{2} \mathrm{O}_{3}(\geq 99 \%)$, and $\mathrm{C}_{6} \mathrm{H}_{8} \mathrm{O}_{7}(\geq 99.5 \%)$ were procured from Duksan Pure Chemical Co. Ltd (Korea). HCl (36 wt\%), $\mathrm{H}_{2} \mathrm{SO}_{4}(\geq 97 \%), \mathrm{Zn}\left(\mathrm{NO}_{3}\right)_{2} \cdot 6 \mathrm{H}_{2} \mathrm{O}(\geq 99.5 \%)$, and $\mathrm{Na}_{2} \mathrm{SO}_{3}(97 \%)$ were procured from Samchun 
Pure Chemical Co. LTD (Korea). Natural graphite powder is a precursor of graphene. All chemical reagents were of analytical grade and organic solvents were used with deionized water.

2.2.Synthesis

\subsubsection{Preparation of quaternary nanocomposite}

The quaternary nanocomposite was synthesized by the Pechini method. The precursor solution was prepared using a 3:2 ratio of ethylene glycol $\left(\mathrm{C}_{2} \mathrm{H}_{6} \mathrm{O}_{2}\right)$ and chelate-cationic citric acid $\left(\mathrm{C}_{6} \mathrm{H}_{8} \mathrm{O}_{7}\right)$. The precursor agents, in a mmol ratio of 0.02:0.03:0.04:0.08, were dispersed into the citric acid solvent and stirred at $60^{\circ} \mathrm{C}$ for $6 \mathrm{~h}$ until it became viscous. The process of preparing the mortar is called chelating, and its main function is to establish a chemical bond between the transition metal and the organic molecules in order to adjust the metal chain. The mixture was transferred into $100 \mathrm{ml}$ Teflon-lined clave and heated at $150^{\circ} \mathrm{C}$ for $15 \mathrm{~h}$, then allowed to cool to room temperature $\left(25^{\circ} \mathrm{C}\right)$. The final product was washed with $\mathrm{DI}$ water and dried at $100^{\circ} \mathrm{C}$, then the powder was calcined at $700^{\circ} \mathrm{C}$ for $2 \mathrm{~h}$. The final nanomaterial was denoted AFNS.

\subsubsection{Preparation of binary and ternary nanocomposite}

The binary and ternary composites were prepared by the Pechini method. The graphene was prepared by Hummer and Offeman's method [30], the details of which were described previously [31]. First, the organic solvent was prepared using absolute ethanol and DI water (volume ratio = 5:4) with continuous stirring at room temperature. Then, $0.7 \mathrm{~g}$ of AFNS was added to the solvent and stirred for $1 \mathrm{~h}$. Graphene $(0.7 \mathrm{~g})$ was added to the mixture, which was stirred at $120^{\circ} \mathrm{C}$ for $6 \mathrm{~h}$, then transferred to a $100 \mathrm{ml}$ Teflon-lined stainless-steel autoclave and heat-treated at $150^{\circ} \mathrm{C}$ for 15 $\mathrm{h}$ before being cooled to $25^{\circ} \mathrm{C}$. The final product was rinsed with DI water, dried completely at $90^{\circ} \mathrm{C}$, and then calcined at $700^{\circ} \mathrm{C}$ for $2 \mathrm{~h}$. The prepared sample was denoted AFNSG. In the next step, $\mathrm{TiO}_{2}$ was combined with AFNSG. The reactants were combined in a molar ratio of ethanol to $\mathrm{H}_{2} \mathrm{O}$ to TNB of $30: 15: 4$ and stirred continuously for $1 \mathrm{~h}$. One-half gram of AFNSG nanocomposite was added to the prepared solution, which was stirred at room temperature for $6 \mathrm{~h}$, then transferred to an autoclave and kept in an electric oven at $150^{\circ} \mathrm{C}$ for $15 \mathrm{~h}$. The obtained product was rinsed with DI water and dried until it became a powder and calcined under the same conditions. The final sample was renamed AFNSGT. The morphology state and electrochemical analysis method was detail explained in the supplementary material.

\subsection{Reduction process}

\subsubsection{Photocatalytic $\mathrm{CO}_{2}$ reduction}

The photoreduction of $\mathrm{CO}_{2}$ was conducted in a three-part closed reactor under light irradiation (Scheme S1). Two different electron-donor scavengers were used in this experiment, which 
provided a supply of cyclic electrons to increase the catalytic activity of the photocatalyst. First, a $0.04 \mathrm{M} \mathrm{NaHCO}_{3}$ solution was prepared. Then, $0.1 \mathrm{~g}$ of photocatalyst and scavenger were dispersed in solvent and stirred for $1 \mathrm{~h}$. A highly pure input gas $\left(\mathrm{CO}_{2}, 99.99 \%\right)$ was purged into the mixture to obtain a gas/solvent mixture; the gas was controlled by the mass flow controller and the total purging time was $30 \mathrm{~min}$. Next, pure nitrogen was purged into the mixture to remove the gas from the glass reactor. The lamp was then switched on and the light source (500 W halide lamp) was placed at the top of the reactor at a distance of about $10 \mathrm{~cm}$. In detail, $100 \mathrm{mg}$ of photocatalyst and $0.3 \mathrm{~g}$ scavenger were dispersed in $0.04 \mathrm{M} \mathrm{NaHCO}_{3}$ containing $50 \mathrm{ml}$ solvent and stirred for $1 \mathrm{~h}$. The pure input gas was controlled by the mass flow controller and the total gaspurging time was $30 \mathrm{~min}$. The total reaction time was 48 hours; every 12 hours, a certain volume of solution was withdrawn from the reactor using a syringe, and the solution was filtered through a membrane filter with a pore size of $0.45 \mu \mathrm{m}$ and a diameter of $47 \mathrm{~mm}$. The amount of alcohol in the solution was analyzed using a "Quantitative analysis of alcohol" method. In this method, $10 \mathrm{ml}$ of $0.1 \mathrm{M} \mathrm{CrO}_{3}$ was added to a $1 \mathrm{ml}$ sample and agitated for $15 \mathrm{~min}$, then the suspension was centrifuged $(10000 \mathrm{ppm} / 15 \mathrm{~min})$. The concentration of the acquired solution was examined by a UV spectrophotometer (Optizen POP, Korea) using a quartz cell $(1 \times 4.5 \mathrm{~cm})$. The functional group of the final methanol was analyzed by a FTIR spectrometer (FTIR iS5, Thermoscience).

\subsubsection{Electrochemical $\mathrm{CO}_{2}$ reduction}

The electrochemical $\mathrm{CO}_{2}$ reduction process was conducted on a PGP201 Potentiastat (A41A009) using a three-electrode system. $\mathrm{Ag} / \mathrm{AgCl}$ and platinum were used as the reference and counter electrode, respectively. The as-prepared binary and ternary nanocomposites were used for the working electrode (WE) preparation. The WE were prepared by following the "Doctor blade" method [32]. Ethyl cellulose was used as a binding material and mixed with the as-prepared nanocomposite in a 1:3 ratio. Then, a few drops of pure ethanol were added, and the resulting mixture was ground and used to veneer the top of the $\mathrm{Ni}$ foil. The electrode preparation process is presented in Scheme S2. The current density determines the amount of electric current per unit cross-section of the material. The input $\mathrm{CO}_{2}$ gas-purging speed and the amount of gas were controlled by the mass-flow controller and $50 \mathrm{ml}$ of $0.04 \mathrm{M} \mathrm{NaHCO}_{3}$ solvent was used as the electrolyte solution. The cyclic voltammetry (CV) measurement was conducted in a potential range of $(-1.2$ to $1.5 \mathrm{~V}$ vs. $\mathrm{Ag} / \mathrm{AgCl})$ at a scan rate of $100 \mathrm{mV} \mathrm{s}^{-1}$. After electrolysis, a voltammogram was obtained for the final product cycle considering the highest oxidation peak current. In a reaction that reduces the electrochemical composition of $\mathrm{CO}_{2}$, the catalyst can direct a specific reaction to produce a certain amount of product. In $\mathrm{CO}_{2} \mathrm{RR}$, the following equation considers the Faraday efficiency (FE) to confirm the selected product during the reaction [33]. 


$$
F E \%=\frac{n_{\text {methanol }} \times n \times F}{\int_{0}^{t} I d t} \times 100
$$

where, $\mathrm{n}_{\text {methanol }}$ is the number of moles of formate and $\mathrm{n}$ represents the number of electrons transferred from $\mathrm{CO}_{2}$ to produce one molecule of methanol. In this case, $\mathrm{n}=6, \mathrm{~F}$ is Faraday's constant $\left(96,485 \mathrm{C} \mathrm{mol}^{-1}\right.$ of electrons), and $\mathrm{I}$ is the circuit current (measured by the Potentiastat). Reaction time $(\mathrm{t})$ is measured in $\mathrm{s}$.

\section{Result and Discussion}

\subsection{XRD analysis and Raman spectra}

Figure 1 (a) and (b) show the crystal structure of the binary and ternary nanocomposite. In the XRD pattern of AFNS, the peaks generally revealed a decent crystal structure and phase. The diffraction peaks were located at $2 \theta=15.63,31.32,37.96$, and $49.85^{\circ}$, which are respectively assigned to the (111), (113), (004) and (115) crystal planes of $\mathrm{FeNi}_{2} \mathrm{~S}_{4}$ (JCPDS. 96-900-0979). After combining with graphene, the diffraction peak becomes sharp; the diffraction peak of graphene was observed at $2 \theta=21.68^{\circ}$, corresponding to the (100) crystal plane. The peak intensity was low because the quantity was low. In the AFNSGT nanocomposite, the XRD peaks of $\mathrm{TiO}_{2}$ were observed at $2 \theta=25.28,38.05$, and $55.02^{\circ}$, which were assigned to the (011), (004) and (121) crystal planes of anatase $\mathrm{TiO}_{2}$ (JCPDS №.21-1272). The reference XRD peak of anatase $\mathrm{TiO}_{2}$ and ternary nanocomposite data is shown in Figure 1 (a). The catalytic activity of the anatase phase is more active than that of the rutile phase, and the electron-hole pair life of anatase is favorable for the surface reaction. The crystallite sizes of each nanocomposite were calculated using the Debye-Scherrer equation; these were found to be 3.37, 6.31, and $3.68 \mathrm{~nm}$. The crystallite sizes of a particle can affect the catalytic activity of the photocatalyst. Several previous research papers $[34,35]$ have analyzed the effect of crystallite size on photocatalytic performance. Figure 1 (b) shows the XRD patterns of the $\mathrm{Ag}_{2} \mathrm{NiS}_{2}, \mathrm{FeNiS}_{2}$ and $\mathrm{AgFeNi} \mathrm{S}_{4}$ semiconductors, which helps to demonstrate the difference between ternary and quaternary semiconductors. The peaks of NiS, $\mathrm{Ag}_{2} \mathrm{~S}$, and FeS were observed in this XRD pattern, as shown in Figure 1 (b). The XRD peaks of AFNS were clear and distinct.

The state of the carbon material (D- and G-band) and molecular interactions between $\mathrm{AgFeNi}_{2} \mathrm{~S}_{4}$, graphene, and $\mathrm{TiO}_{2}$ were confirmed by the results of Raman spectroscopy. The full Raman data of the binary and ternary nanocomposites are shown in detail in Figure 1 (c). In AFNSG, graphene had two sharp peaks in the 1348.6 and $1588.2 \mathrm{~cm}^{-1}$ shift region, which indicates $A_{1 g}$ and $E_{2 g}$ symmetry (D- and G-mode). The two types of feature peaks were observed 
at 1390 and $1583 \mathrm{~cm}^{-1}$ [36]. The peak position shifted from the lower to the higher region or vice versa. The quaternary semiconductor had one wide and sharp peak in the $551.5 \mathrm{~cm}^{-1}$ region. According to previous studies, chalcogenide-based semiconductors have characteristic peaks in the $100-600 \mathrm{~cm}^{-1}$ region [37]. Some main peaks were not observed in the current study due to modification of the crystal lattice vibrations of the nanomaterial. AFNSGT included five main peaks, which were assigned to $\mathrm{TiO}_{2}$ and graphene. The Raman band of anatase-structured $\mathrm{TiO}_{2}$ was obtained in the $100-700 \mathrm{~cm}^{-1}$ shift region, which included the $E_{g}, B_{1 g}$, and $A_{1 g}$ modes [38]. The $E_{\mathrm{g}}$ mode peak appeared at $613.5 \mathrm{~cm}^{-1}$, the $\mathrm{B}_{1 \mathrm{~g}}$ mode peak was observed at $420.4 \mathrm{~cm}^{-1}$, and the last peak, SEO, appeared at $292.6 \mathrm{~cm}^{-1}$, which indicates the motions of atoms. The characteristic peaks of the quaternary semiconductors were not present in AFNSGT because the symmetric motion of quaternary semiconductors was distorted and the peak intensity of $\mathrm{TiO}_{2}$ was sharp and strong. The peak position of the D- and G-band was shifted from the higher to the lower shift regions. Shifting of peaks towards a lower or higher wave number is related to chemical bond length. If the chemical bond length of the molecules changes for any internal or external reasons, the wave number may shift. Based on the above theory, the chemical bond length of graphene changed due to the bonding interaction between graphene and $\mathrm{TiO}_{2}$.

The $\mathrm{I}_{\mathrm{D}} / \mathrm{I}_{\mathrm{G}}$ ratio was 0.85 in AFNSG and 0.84 in AFNSGT. The change in the value indicated the presence of lattice defects, which arise from the combination of a metal chalcogenide and graphene.

\subsection{Morphological analysis}

The surface of the photocatalyst was analyzed via SEM. Figure 2 (a) and (b) show the SEM analysis of the quaternary semiconductors, which were wrinkled and elliptical. The preparation of the quaternary semiconductor based on the Pechini method helped to establish a chemical bond between the transition metal and the organic molecules in order to adjust the metal chain. This could demonstrate successful fabrication of the metal chalcogenide semiconductor. After combining with graphene, all particles agglomerated on the graphene exterior owing to the functional group on the graphene surface. The variously structured particles were irregularly agglomerated, as shown in Figure 2 (c)-(d). In the SEM image of AFNSGT, the $\mathrm{TiO}_{2}$ particle showed a white, wrinkled and oval structure. Figure 2 (e) and (f) demonstrate the successful fabrication of $\mathrm{AgFeNi}_{2} \mathrm{~S}_{4}-\mathrm{Graphene}_{-} \mathrm{TiO}_{2}$. Furthermore, the successful interconnection of $\mathrm{AgFeNi}_{2} \mathrm{~S}_{4}$, graphene and $\mathrm{TiO}_{2}$ can be helpful for formation of the hetero-junction structure with good charge carrier properties. The role of graphene is as a bridge and electron acceptor that can support the photogenerated charge carrier and increase the photocatalytic capacity. Figure 2 shows 
the 3D surface plot, which reveals the roughness of each sample. The surface of AFNS was uneven and sharp, while that of AFNSG was convex. The surface of AFNSGT was smooth and convex.

The internal structure and crystallographic facet of each nanocomposite were analyzed by TEM and HRTEM. Figure 3 (a) shows the presence of the quaternary semiconductor as an elliptical structure on the graphene, which indicates the successful interaction between AFNS and graphene. The morphology of graphene was clear and provided the large surface needed for growth of the metal compound, as shown in Figure S1 (a)-(b). As shown in Figure 3 (d), the pentagonal $\mathrm{TiO}_{2}$ appeared as a dark black entity that was uniformly spread on the graphene exterior in the AFNSGT ternary nanocomposite. The $\mathrm{TiO}_{2}$ and quaternary semiconductors were evenly distributed on the surface of graphene. The oxygenated functional group on the graphene exterior prevents the formation of metal or metal oxide agglomerates. Figure 3 (b) and (e) show the HRTEM findings of the crystallographic facets of each nanocomposite. The lattice fringes show the d-spacing values of the quaternary semiconductor and $\mathrm{TiO}_{2}, 0.235 \mathrm{~nm}$ and $0.351 \mathrm{~nm}$, respectively, corresponding to the AFNS (201) and $\mathrm{TiO}_{2}(101)$ crystal planes, as shown in Figure 3 (b) and (e). The average particle size histograms of the binary, ternary and quaternary semiconductors are shown in Figure 3 (c), (f) and (g). The average particle sizes were 3.08 (AFNS in AFNSG), 2.75 (AFNS in AFNSGT), and $3.08 \mathrm{~nm}$ ( $\mathrm{TiO}_{2}$ in AFNSGT).

Additionally, quantitative element analysis was done using an EDX instrument. Figure 4 shows the microanalyses of all as-synthesized samples, which reveal the presence of the main elements. Ag, Fe, Ni, S, Ti, and $\mathrm{O}$ were obtained from the metal and metal-oxide component, and $\mathrm{C}$ was derived from the main adsorbent material, graphene, in the ternary photocatalyst. Each element had its own $\mathrm{K} \alpha$ and $\mathrm{K} \beta$ values in the appropriate region. These elemental analyses are summarized in the 3D pie graph.

\subsection{FTIR and XPS analysis}

FTIR was used to identify the presence of the functional groups of the nanocomposites. Figure 5 shows the FTIR results of the nanocomposites. The adsorption band of the carbonyl group (C-O) appeared at $1582.9 \mathrm{~cm}^{-1}$, the carboxylic acid group (-COOH) was observed at $1412.1 \mathrm{~cm}^{-1}$, and asymmetric and symmetric stretching of $\mathrm{C}-\mathrm{O}-\mathrm{C}$ appeared at the wave number regions of 1089.7 and $617.3 \mathrm{~cm}^{-1}$. All of those peaks corresponded to graphene [39]. The blue line revels the adsorption peaks for AFNS at 2917.8, 1433.0, 1117.9, 998.0, 665.2 and $622.9 \mathrm{~cm}^{-1}$, which were ascribed to the $(\mathrm{R}-\mathrm{C}(\mathrm{O})-\mathrm{OH}),(\mathrm{C}(\mathrm{O})-\mathrm{OH}), \mathrm{S}=\mathrm{O}, \mathrm{CH}_{2}$ rocking, $\mathrm{Fe}-\mathrm{O}$ and $\mathrm{S}-\mathrm{O}$ vibration mode [40]. Most of the peaks were ascribed to the citric acid and the adsorption bands, confirming the 
successful chemical bonding state of the metal chalcogenide semiconductor. After combination with graphene, the peak intensity and vibration mode changed due to the interaction between graphene and AFNS. In the FTIR spectra of AFNSGT, the wide adsorption band of the Ti-O-Ti of $\mathrm{TiO}_{2}$ appeared at 1079.49 and $584.5 \mathrm{~cm}^{-1}$ [41]. The FTIR analysis of the samples confirmed the successful formation of the $\mathrm{AgFeNi}_{2} \mathrm{~S}_{4}-\mathrm{Graphene}^{-\mathrm{TiO}_{2}}$ ternary nanocomposite.

XPS was used to analyze the chemical states and interactions among $\mathrm{AgFeNi}_{2} \mathrm{~S}_{4}$, graphene, and $\mathrm{TiO}_{2}$. Figure 6 shows the XPS spectrum of each element. The binding energy depends on the chemical interactions and form of the samples. Figure 6 (a) shows the XPS survey spectra, which indicated the existence of each element and confirmed the successful formation of AFNSGT. Figure 6 (b) shows two peaks at the 368.35 and $374.37 \mathrm{eV}$ binding regions, which are related to the $\mathrm{Ag} 3 \mathrm{~d}_{5 / 2}$ and $\mathrm{Ag} 3 \mathrm{~d}_{3 / 2}$ spectra of $\mathrm{Ag}$ (I) in AFNSGT [42]. The XPS spectrum of Fe2p (Figure 6 (c)) displayed four deconvoluted peaks at 711.14, 714.89, 724.76, and $731.75 \mathrm{eV}$. The photoelectron peak at $711.14 \mathrm{eV}$ corresponds to the binding energy of $\mathrm{Fe}^{3+} 2 \mathrm{p}_{3 / 2}$, while the peak at $724.76 \mathrm{eV}$ can be assigned to $\mathrm{Fe}^{2+} 2 \mathrm{p}_{3 / 2}$. The peak at $731.75 \mathrm{eV}$ corresponds to the $2 \mathrm{p}_{1 / 2}$ of $\mathrm{Fe}$ (II) and Fe (III) ions [43]. The last peak, at $714.89 \mathrm{eV}$, is a satellite peak that indicates the coexistence of $\mathrm{Fe}$ (II) and $\mathrm{Fe}$ (III) in the quaternary semiconductor. Figure 6 (d) shows that the Ni2p XPS spectrum was deconvoluted into two spin-orbit doublets. The photoelectron peaks at 856.52 and $873.72 \mathrm{eV}$ indicate the $2 \mathrm{p}_{3 / 2}$ and $2 \mathrm{p}_{1 / 2}$ spin orbitals of $\mathrm{Ni}^{3+}$. The other two peaks are assigned to the high-spin divalent state (satellite peaks) of $\mathrm{Ni}^{2+}$ [44]. The S2p XPS spectrum consisted of four peaks, located at 163.86, 165.04, 169.29, and $170.35 \mathrm{eV}$, as shown in Figure 6 (e). These four peaks can be assigned to monosulfide $\left(\mathrm{S}^{2-}\right)$ and disulfide $\left(\mathrm{S}_{2}{ }^{2-}\right)$ [45]. The XPS peaks of sulfide were observed at $158-161 \mathrm{eV}$, and the disulfide peaks were located in the $162-168 \mathrm{eV}$ region.

The electron configuration of $\mathrm{C} 1 \mathrm{~s}$ consists of three peaks, which correspond to the $\mathrm{C}-\mathrm{C}$ (aliphatic), C-O-C, and $\mathrm{C}=\mathrm{O}$ groups, as shown in Figure 6 (f) [46]. The high-resolution Ti2p spectrum of AFNSGT displayed two peaks at 459.42 and $465.18 \mathrm{eV}$, which are related to $\mathrm{Ti}^{4+} 2 \mathrm{p}$ $3 / 2$ and $\mathrm{Ti}^{4+} 2 \mathrm{p}_{1 / 2}$. In addition, the $2 \mathrm{p}_{3 / 2}$ spin-orbitals clearly indicate the presence of $\mathrm{Ti}(\mathrm{IV})$; the ratio of these two peaks is 2:1, as shown in Figure $6(\mathrm{~g})$ [47]. The O1s spectrum is composed of four peaks, located at $530.7,532.65,532.69$ and $535.34 \mathrm{eV}$. The first peak is related to the C-O group, whereas the second peak is assigned to the metal-carbonate forms $(\mathrm{O}-\mathrm{Me})$, as shown in Figure 6 (h) [48]. The existence of the metal carbonate forms confirms the interaction between metal and oxygen. The next two peaks correspond to the carbonyl and carboxyl groups.

3.4. PL, photocurrent response, Nyquist plot and DRS analysis 
The charge transfer and interactions among $\mathrm{AFNS}, \mathrm{TiO}_{2}$, and graphene were studied using the DRS, photocurrent response, PL, and EIS methods. The charge separation capacity of $\mathrm{AgFeNi}_{2} \mathrm{~S}_{4}-$ Graphene- $\mathrm{TiO}_{2}$ was analyzed by the PL method. The intensity of PL depends on the recombination rate of the electron-hole pairs; a decrease in PL intensity indicates that the charge carrier has a long lifetime. All photocatalysts showed a light response under the $514 \mathrm{~nm}$ laser, as shown in Figure 7 (a). The emission peaks of the samples appeared in the $540-660 \mathrm{~nm}$ range, in the visible light region. In the PL spectra, two sharp emission peaks appeared, at wavelengths of 546.51 and $551.95 \mathrm{~nm}$. Additionally, pure AFNS and AFNSG had wide emission peaks near $604.66 \mathrm{~nm}$. The wide-emission peak area and shape changed after the addition of $\mathrm{TiO}_{2}$ to yield AFNSG. The emission peak of the metal-based composite was classified in two sectors: (1) UV emission (NBE) and (2) visible emission (DF defect) [49]. The rapid charge recombination rate of AFNS is confirmed by the high-intensity PL peak. The PL peak intensity was reduced in AFNSG due to the high conductivity and charge transfer capacity of the 2D-structured graphene. In AFNSGT, the intensity of the peak was somewhat reduced due to the efficient interfacial contact between each part, which bolstered the charge carrier separation. The results of the above analysis show that the proposed ternary nanocomposite, consisting of a metal chalcogenide, graphene and $\mathrm{TiO}_{2}$, has a high charge carrying capacity. The low PL intensity reflected the recombination rate of electron and holes, which is related to rapid conversion from $\mathrm{CO}_{2}$ into hydrocarbon fuel.

The photocurrent response of all samples showed repeatable signals in fewer than five on-off cycles, as shown in Figure 7 (b). All nanocomposites had a prompt and stable photocurrent response for each cycle. The photocurrent response decayed in the dark but recuperated within 60 $\mathrm{s}$ once the light was turned on. The above procedure can be described in terms of the presence of charge transmission from VB to CB under light irradiation. The 2D-structured graphene had a low current value $\left(2.156 \times 10^{-6} \mathrm{~mA} / \mathrm{cm}^{2}\right)$ in each cycle. The pure quaternary nanocomposite had a lower current value $\left(2.818 \times 10^{-6} \mathrm{~mA} / \mathrm{cm}^{2}\right)$ in every cycle, which indicated low separation efficiency of the photo-generated charge. AFNSG has efficient photo-generated charges because of its good photocurrent response $\left(1.091 \times 10^{-5} \mathrm{~mA} / \mathrm{cm}^{2}\right)$; the graphene supports charge separation and promotes electron flow in the light-on state. AFNSGT showed a higher photocurrent value $\left(1.272 \times 10^{-5} \mathrm{~mA} / \mathrm{cm}^{2}\right)$ than did AFNS during six on-off cycles of light irradiation. The final ternary photocatalyst may show better catalytic activity due to the efficient separation of photogenerated charges and interfacial contact among $\mathrm{AgFeNi}_{2} \mathrm{~S}_{4}$, graphene, and $\mathrm{TiO}_{2}$, and each nanocomposite had high conductivity.

Figure 7 (c) shows the electrochemical impedance spectroscopy (EIS) findings of all samples. The EIS profile is identical to the charge transfer resistance across the electrode/electrolyte. A 
wide semicircle profile is indicative of a poor charge carrier with low conductivity. Conversely, a small semicircle can indicate good conductivity with an effective charge carrier, and thus confirm the high catalytic performance of a photocatalyst. Figure 9 (c) shows the Nyquist plot of all samples at room temperature for the frequency range from 5 to $1 \mathrm{mHz}$ with a half-cell. The AFNSGT sample had a smaller semicircle than did the pure AFNS and AFNSG samples. The size of the semicircle depends on the chemical composition and degree of interconnection of AFNS, graphene, and $\mathrm{TiO}_{2}$. Graphene had a small semicircle profile because its high electrical conductivity is capable of sustaining the conductivity of the quaternary chalcogenide nanocomposite. The semicircular profile of the AFNSG binary nanocomposite is located between that of AFNS and AFNSGT, depending on the electrical conductivity and interfacial connection of AFNS and graphene. Figure 7 (d) shows the DRS spectra of the samples. All samples had light responses in the visible and UV light regions. Figure 7 (e) expresses the bandgap energy value of the unary, binary and ternary nanocomposites.

The band gap energy value of each nanocomposite was computed by UV-vis DRS, using Equation [1] [50]:

$$
\left[h v F\left(R_{\infty}\right)\right]^{1 / \mathrm{n}}=A\left(h v E_{g}\right)
$$

where $E_{\mathrm{g}}$ is the energy of the band gap, $F(R)(1 R)^{2} / 2 R$ is the Kubelka-Munk function, $A$ is the constant of proportionality, and $F(R)$ is the absorption coefficient. $h v=h c / \lambda$ is the energy of the incident photon. The calculated band gaps of the three nanocomposites were 2.67, 2.59, and 1.95 $\mathrm{eV}$; the band gap value of AFNSGT was lower than that of AFNS and AFNSG. The band gap energy analysis confirmed that AFNSGT had high catalytic activity and efficiently reduced $\mathrm{CO}_{2}$ into methanol. Nickel sulfide-based or quantum dot united carbonaceous materials or semiconductor photocatalysts are generally used for $\mathrm{H}_{2}$ evolution [35-36]. The one-spot and seedmediated hydrothermal methods and a sol-gel method are commonly used to prepare NiS photocatalysts $[2,3]$. The structure of the photocatalyst is the main factor that determines catalytic activity. Recently, ternary structured nanocomposites have become popular in the catalytic field because of their advantages over binary materials, which include strong light absorption rates and enhanced photocatalytic potency. In the last decade, several studies have reported on use of NiSbased photocatalysts for $\mathrm{CO}_{2}$ reduction under light illumination [37-39].

According to our analysis, the ternary nanocomposite formed successfully and showed a high degree of interconnectivity, highly efficient charge transfer, and suppression of the photogenerated $\mathrm{e}^{-}$and $\mathrm{h}^{+}$recombination rate. Also, the combination of $2 \mathrm{D}$ graphene and $\mathrm{TiO}_{2}$ with a metal semiconductor showed more intimate contact, superior electronic coupling, and a more sensitive photosensitizer, which may lead to better $\mathrm{CO}_{2}$ reduction under light irradiation. Based on the 
results of both previous studies and the current study, we assume that the ternary nanocomposite has high photocatalytic activity for $\mathrm{CO}_{2}$ reduction.

Currently, ternary chalcogenide photocatalyst materials are commonly used in $\mathrm{CO}_{2}$ evolution, including $\mathrm{ZnO} / \mathrm{ZnSe}$ [51], $\mathrm{WO}_{3}-\mathrm{TiO}_{2} / \mathrm{Cu}_{2} \mathrm{ZnSnS}_{4} \quad$ [52], and $\mathrm{NiS} / \mathrm{CQDs} / \mathrm{ZnIn}_{2} \mathrm{~S}_{4}$ [53-54] nanomaterials. $\mathrm{AgFeNi}_{2} \mathrm{~S}_{4}-\mathrm{Graphene}^{-\mathrm{TiO}_{2}}$ exhibits higher photocatalytic $\mathrm{CO}_{2}$ conversion activities than did the other ternary chalcogenide photocatalysts. Therefore, a noble metal joined quaternary chalcogenide catalyst can still achieve high-efficiency $\mathrm{CO}_{2}$ reduction. The utility of $\mathrm{TiO}_{2}$ in the $\mathrm{CO}_{2}$ photoreduction test is due to the band gap and the location of the energy band, which is comparable to the $\mathrm{CO}_{2}$ reduction capacity and $\mathrm{H}_{2} \mathrm{O}$ oxidation capacity. Theoretically, redox reactions could be occurring on $\mathrm{TiO}_{2}$ due to its conduction band energy and valence band energy being available to reduce $\mathrm{CO}_{2}$ to formic acid and methanol, and to oxidize $\mathrm{H}_{2} \mathrm{O}$ to form $\mathrm{H}^{+}$.

In addition, an NiS-based photocatalyst has p-type semiconductor properties, which are favorable to water oxidation and do not strongly affect $\mathrm{CO}_{2}$ reduction. The combination of $\mathrm{TiO}_{2}$ and $\mathrm{AgFeNi}_{2} \mathrm{~S}_{4}$ was evenly spread across the graphene exterior and the successful interaction of those nanocomposites can determine the band structure and photocatalytic potency of the newly modeled ternary nanocomposite.

\subsection{Evolution of $\mathrm{CO}_{2}$ into methanol}

The conversion of $\mathrm{CO}_{2}$ to methanol was carried out by two different experimental methods, photocatalytic and electrochemical. According to the test results, the newly modeled ternary nanocomposite had high catalytic activity and successfully reduced $\mathrm{CO}_{2}$ into methanol. Figure 8 ((a), (c) and (e)) shows the quantification of the final methanol yield under different light conditions. The unary, binary, and ternary nanocomposites were used for the photocatalytic reduction of $\mathrm{CO}_{2}$ to methanol. The entire test process was carried out under two different conditions, with-scavenger and without-scavenger. The final concentration of methanol was analyzed by the "Quantitative Analysis of Alcohol" method using $\mathrm{CrO}_{3}$ as a strong oxidizing agent. During the experiment, the final methanol was oxidized, and the oxidation state of $\mathrm{CrO}_{3}$ decreased. The color of the base solution changed - as the methanol concentration increased, the oxidation state of $\mathrm{CrO}_{3}$ decreased, and the color of the base solution changed accordingly. Figure 8 (a) shows the final methanol yield over the AFNS unary photocatalyst under different types of light irradiation for 48 hours. Under visible light, the highest methanol yield was $2.339 \%$, in the withscavenger condition. During UV radiation, the methanol yield increased to 4.136\%; this increase in yield was directly related to the effect of ultraviolet photon energy. The band gap value of the AFNS was $2.67 \mathrm{eV}$, which confirms that the newly modelled quaternary semiconductor showed a 
light response for both visible and UV light. Figure 8 (b) shows the cyclic voltammogram of the AFNS working electrode in the $\mathrm{CO}_{2}$-dissolved solution and the final product at a scan rate of 100 $\mathrm{mV} \mathrm{s}^{-1}$. The $\mathrm{CV}$ graph occurred in a negative potential range $(-0.9$ to $-0.05 \mathrm{~V})$ on the AFNS working electrode system. The results of the post-electrolysis test show that the highest oxidation peak appeared around $1.20 \mathrm{~V}$ (vs. $\mathrm{Ag} / \mathrm{AgCl}$ ). The cyclic voltammogram was performed under pure methanol conditions using the as-prepared working electrodes, and the highest oxidation peaks were found in the potential range of 0.39 to $1.20 \mathrm{~V}(\mathrm{~V}$ vs. $\mathrm{Ag} / \mathrm{AgCl})$, as shown in Figure S2. The abovementioned results suggest that unary nanomaterials play an important role in reducing carbon dioxide to methanol. Figures 8 (c) and (d) show the results of methanol production with the AFNSG nanocomposites. The experimental results confirm that the $\mathrm{CO}_{2}$ conversion efficiency of this catalyst is better than that of the AFNS quaternary nanocomposite. The methanol yields were $3.592 \%$ and $4.845 \%$ in the without-scavenger condition. The methanol yields were increased to $4.738 \%$ and $6.349 \%$ in the system with the electron-donor scavenger. In the cyclic voltammogram, the highest oxidation peak appeared at a potential of approximately $1.2 \mathrm{~V}$ (vs. $\mathrm{Ag} / \mathrm{AgCl})$ and the current density increased.

Compared to the unary and binary composites, the ternary composite showed high conversion efficiency for the $\mathrm{CO}_{2}$ evolution reaction. Continuous production of $\mathrm{CH}_{3} \mathrm{OH}$ was obtained using all types of samples, but there was an increasing trend in the evolution of $\mathrm{CH}_{3} \mathrm{OH}$ that was directly related to the properties of the photocatalyst. The methanol yields were increased when AFNSGT was used due to the properties of $2 \mathrm{D}$-structured graphene. The graphene increases the light absorption rate and conductivity, which strongly enhances the photocatalytic potency of the AFNSGT ternary nanocomposite. The highest methanol yields were obtained when using AFNSGT nanocomposite; the yields were 5.504 and $5.971 \%$ under the without-scavenger condition. The methanol yields increased by approximately 1.5 -fold and the highest yields were obtained when using the AFNSGT nanocomposite under light irradiation. The highest methanol evolution of 6.291 and $8.679 \%$ was achieved over AFNSGT in the with-scavenger condition. The $\mathrm{CV}$ graph appeared in a negative potential range (-0.9 to $-0.76 \mathrm{~V})$ in a $\mathrm{CO}_{2}$-dissolved solution. In addition, AFNSGT showed a high $\mathrm{CO}_{2}$ conversion efficiency in the electrochemical reduction process. In the cyclic voltammogram data, the highest oxidation peaks appeared at $1.18 \mathrm{~V}$ (V vs. $\mathrm{Ag} / \mathrm{AgCl}$ ), as shown in Figure 8 (f). The abovementioned $\mathrm{CV}$ graph location is the same as that shown in Figure S2. This result suggests that ternary nanomaterials play an important role in reducing carbon dioxide to methanol.

The results of the abovementioned photocatalytic experiments imply that the best $\mathrm{CO}_{2}$ reduction was obtained in the UV light region, because UV light can supply efficient photon 
energy which can activate the photocatalyst. To increase the $\mathrm{CO}_{2}$ reduction and catalytic activity of the nanocomposite, the electron-donor scavenger $\left(\mathrm{Na}_{2} \mathrm{SO}_{3}\right)$ was used because it allows $\mathrm{CO}_{2}$ to combine with water. There are two reasons for this phenomenon: (i) an increase in the amount of dissolved $\mathrm{CO}_{2}$, and (ii) a reduction in recombination of hole-electron pairs, leading to a longer decay time of surface electrons and facilitation of $\mathrm{CO}_{2}$ reduction.

Prior to the electrochemical procedure, a $0.04 \mathrm{M} \mathrm{NaHCO}_{3}$ solution was placed in a sealed three-electrode glass cell and a $\mathrm{CO}_{2}$-saturated electrolyte was prepared by blowing $\mathrm{CO}_{2}$ at a pressure of $0.2 \mathrm{~kg} / \mathrm{cm}^{2}$ for $30 \mathrm{~min}$. Three different types of electrodes were used during the experiment, and the $\mathrm{CO}_{2}$-dissolved solution was electrolyzed. After electrolysis, a voltammogram was obtained for the final product, taking into account the highest oxidation peak current. The cyclic voltammogram test was performed under two different conditions: (i) $\mathrm{CO}_{2}$-dissolved solution before electrolysis, and (ii) methanol solution after electrolysis.

The electrochemical mechanism of $\mathrm{CO}_{2}$ reduction was determined by analyzing the Faraday efficiency of the final product. According to Equation (1), thermodynamically, 6 electrons are required for the conversion of $\mathrm{CO}_{2}$ to methanol:

$$
\mathrm{CO}_{2}+6 \mathrm{H}^{+}+6 \mathrm{e}^{-}=\mathrm{CH}_{3} \mathrm{OH}+\mathrm{H}_{2} \mathrm{O}
$$

The Faraday efficiency of the quaternary nanocomposite was $25.46 \%$. The value of the Faraday efficiency increased in the AFNSG binary nanocomposite due to the junction of 2Dstructured graphene and metal chalcogenide quaternary photocatalyst, and the final calculated efficiency was around $39.97 \%$. The value of the Faraday efficiency for the AFNSGT ternary nanocomposite increased to $44.25 \%$, proving that the successful design of the newly modeled nanocomposite increases the activity of the working electrode and has a positive effect on the electrochemical reduction of $\mathrm{CO}_{2}$. The peak separation and peak current state depend on the electron transfer properties of the working electrode.

Stability and reusability are the main factors that define the sturdiness of a photocatalyst in practical applications. In the recycling test, the photocatalyst (AFNSGT) was used four times (192 h) under light irradiation with ( $0.3 \mathrm{~g})$ and without scavengers in the $\mathrm{CO}_{2}$ evolution reaction. The ternary photocatalyst was very sturdy during four cycles, with no significant deactivation towards methanol production, as shown in Figure 9. According to the recycling test, the ternary photocatalyst can be considered for generation of solar fuels in practical applications. The recombination rate of the hole-electron pairs is the main parameter that defines the catalytic activity of the photocatalyst. The electron-donor scavenger (sodium sulfite) can reduce the recombination rate of the pairs and increase the number of electrons, while also acting as a 
sufficient cyclic electron donor. Together, these factors produce a photocatalyst with excellent activity.

FTIR was used to identify the presence of the final products and semi-product. The final methanol product (after 1 and 4 cycles) and commercial methanol solution were used in this FTIR analysis. The FTIR spectrum of methanol, which is shown in Figure S3, consisted of four characteristic peaks located at the theoretical peak region. All key data are summarized in Table S1. The FTIR spectrum of all samples was exhibited in a range of $600-3900 \mathrm{~cm}^{-1}$. The peak location and intensity of the reference and methanol products were the same, which confirms that the ternary photocatalyst reduced the $\mathrm{CO}_{2}$ into methanol. During the test, the semi-product was withdrawn from the reactor and analyzed by FTIR. The results suggest that the chemical structure of $\mathrm{CO}_{2}$ had changed and confirmed that carbon dioxide can be reduced to methanol.

The $\mathrm{CO}_{2}$ reduction pathway can be described by a chemical reaction, given below. The reduction of $\mathrm{CO}_{2}$ to methanol involves unique reaction pathways. In general, the reduction of $\mathrm{CO}_{2}$ requires a more negative potential level in the conduction band $(\mathrm{CB})$, while water oxidation needs a more positive level in the valence band (VB), thereby increasing the number of protons and enhancing the reduction of carbon dioxide. Under Vis/UV light irradiation, both $\mathrm{AgFeNi}_{2} \mathrm{~S}_{4}$ and $\mathrm{TiO}_{2}$ absorb energy from photons, and electrons are excited from VB to CB. Graphene can accelerate the charge carrier between AFNS and $\mathrm{TiO}_{2}$ and suppress charge recombination.

$$
\begin{aligned}
& \mathrm{TiO}_{2}+\mathrm{hv} \rightarrow \mathrm{e}^{-}\left(\mathrm{TiO}_{2}\right)+\mathrm{h}^{+}\left(\mathrm{TiO}_{2}\right) \\
& \operatorname{AgFeNi}_{2} S_{4}+h v \rightarrow e^{-}\left(\operatorname{AgFeNi}_{2} S_{4}\right)+h^{+}\left(\operatorname{AgFeNi}_{2} S_{4}\right) \\
& \mathbf{e}^{-}\left(\mathrm{TiO}_{2}\right)+\text { Graphene } \rightarrow \mathrm{TiO}_{2}+\mathbf{e}^{-} \text {(Graphene) } \\
& \mathrm{e}^{-}(\text {Graphene }) \operatorname{AgFeNi}_{2} \mathrm{~S}_{4} \rightarrow \operatorname{Graphene}^{-} \mathrm{e}^{-}\left(\operatorname{AgFeNi}_{2} \mathrm{~S}_{4}\right) \\
& \mathrm{H}_{2} \mathbf{O}+\mathbf{h}^{+} \rightarrow \mathbf{H}^{+}+\mathbf{O H}^{-} \\
& \mathrm{CO}_{2}+\mathrm{e}^{-} \rightarrow \mathrm{CO}_{2}^{--} \\
& \mathrm{CO}_{2}^{+}+2 \mathrm{H}^{\cdot}+2 \mathrm{e}^{-}=\mathrm{HCO}_{2} \mathrm{H} \quad(\text { Formic acid) } \\
& \mathrm{CO}_{2}+2 \mathrm{H}^{+}+2 \mathrm{e}^{-} \rightarrow \mathrm{CO}+\mathrm{H}_{2} \mathrm{O} \text { (Carbon monoxide) } \\
& \mathrm{CO}_{2}+4 \mathrm{H}^{+}+4 \mathrm{e}^{-} \rightarrow \mathrm{HCHO}+\mathrm{H}_{2} \mathrm{O} \text { (Formaldehyde) } \\
& \mathrm{CO}_{2}+6 \mathrm{H}^{+}+6 \mathrm{e}^{-} \rightarrow \mathrm{CH}_{3} \mathrm{OH}+\mathrm{H}_{2} \mathrm{O} \text { (Methanol) }
\end{aligned}
$$

Eqs. (2) - (5) describe the activation states of $\mathrm{AgFeNi}_{2} \mathrm{~S}_{4}, \mathrm{TiO}_{2}$, and graphene that enable them to produce photoexcited electron-hole pairs. Eqs. (7) - (11) describe the redox reaction, in which the holes are used for oxidation and the electrons are used for reduction. The positively charged holes reacted with water to form hydrogen, and this hydrogen source favored the formation of 
methanol. Meanwhile, the purged $\mathrm{CO}_{2}$ was adsorbed on the surface of the photocatalyst, so the photo-excited electrons on the surface can reduce/convert the $\mathrm{CO}_{2}$ into methanol. The conversion of $\mathrm{CO}_{2}$ into $\mathrm{CH}_{3} \mathrm{OH}$ required $6 \mathrm{e}^{-} / 6 \mathrm{H}^{+}$.

\section{Conclusion}

In conclusion, we successfully fabricated a new ternary nanocomposite by the Pechini method. The advantage of the Pechini method is that it allows us to create a chemical interaction between the transition metal and organic molecules to form a metal chain. The morphology, functional groups and electrochemical properties of the unary, binary and ternary nanocomposites were analyzed by spectroscopic techniques. The ternary structured nanocomposite had more stable properties and charge carrier separation due to the presence of $2 \mathrm{D}$-structured graphene, $\mathrm{TiO}_{2}$ and the quaternary semiconductor. 2D-structured graphene can act as a bridge between the semiconductor $\left(\mathrm{TiO}_{2}\right)$ and a quaternary semiconductor that increases light absorption and enhances photo-generated charge transfer. The conduction band structure of $\mathrm{TiO}_{2}$ makes it available to reduce carbon dioxide to methanol under light irradiation, thus enhancing the catalytic activity of the ternary nanocomposite. The $\mathrm{CO}_{2}$ reduction process was conducted through photocatalytic and electrochemical methods. The highest methanol evolutions of 6.291 and $8.679 \%$ were achieved over AFNSGT, while methanol yields of 4.738 and $6.349 \%$ were achieved over the AFNSG nanocomposite in the photocatalytic process. The ternary catalyst was reusable after four cycles, which confirmed that the newly modeled nanocomposite will be useful for practical applications. In electrochemical $\mathrm{CO}_{2}$ reduction, the Faraday efficiency is the main parameter that defines the performance of the working electrode and the evolution of methanol. The Faraday efficiency of AFNSGT increased to $44.25 \%$, which proves that that the successful design of the newly modeled nanocomposite increases the activity of the working electrode and has a positive effect on the electrochemical reduction of $\mathrm{CO}_{2}$. In this work, we synthesized the $\mathrm{AgFeNi}_{2} \mathrm{~S}_{4}$ Graphene- $\mathrm{TiO}_{2}$ ternary nanocomposite by the Pechini method. The catalytic activity tests confirmed that the ternary nanocomposite had high catalytic activity for photocatalytic and electrochemical reduction of $\mathrm{CO}_{2}$. This work confirms that the new structured nanomaterial can be applied to reduce environmental pollution and fabricate hydrocarbon fuels.

\section{Acknowledgments}

This work was supported by the Research Foundation of Hanseo University in 2021. The authors are grateful to the staff of the University for financial support. 



\section{DECLARATIONS}

\section{-Ethical Approval}

We had kept the Ethical fields in all of terms. In this research process, we did not use any illegal and inhibited human test, drug and instrument.

\section{-Consent to Participate}

We confirm that the manuscript has been read and approved by all named authors and that there are no other persons who satisfied the criteria for authorship but are not listed.

\section{-Consent to Publish}

We further confirm that the order of authors listed in the manuscript has been approved for this publication by all of us.

\section{-Authors Contributions}

We understand that the Corresponding Author is the sole contact for the Editorial process He is responsible for communicating with the other authors about experimental progress, submissions of revisions and final approval of proofs. We confirm that we have provided a current, correct email address which is accessible by the Corresponding Author and which has been configured to accept email from.

\section{-Funding}

For the publication, there has been no significant financial support for this work that could have influenced its outcome.

\section{-Competing Interests}

We wish to confirm that there are no known conflicts of interest associated with this publication

\section{-Availability of data and materials}

We the undersigned declare that this manuscript is original with new data and synthesized novel materials, has not been published before and is not currently being considered for publication elsewhere. 


\section{Reference}

1. Xu, F.; Zhang, J.; Zhu, B. CuInS 2 sensitized $\mathrm{TiO}_{2}$ hybrid nanofibers for improved photocatalytic $\mathrm{CO}_{2}$ reduction. J. Appl. Catal. B Environ. 2018a, 230, 194-202.

2. Habisreutinger, S.N.; Schmidt-Mende, L.; Stolarczyk, J.K. Photocatalytic reduction of $\mathrm{CO}_{2}$ on $\mathrm{TiO}_{2}$ and other semiconductors. J. Angew. Chem. Int. Ed. 2013, 52 (29), 7372-7408.

3. Windle, C.D.; Perutz, R.N. Advances in molecular photocatalytic and electrocatalytic $\mathrm{CO}_{2}$ reduction, Coordinator. Chem. Rev. 2012, 256, 2562.

4. Qu, Q.; Duan, X.F. One-dimensional homogeneous and heterogeneous nanowires for solar energy conversion J. Mater. Chem. 2012, 22, 16171-16181.

5. Thomas, F.H.; Timothy, T.C.; Nicholas, H. F. Life cycle greenhouse gas assessment of a coalfired power station with calcium looping $\mathrm{CO}_{2}$ capture and offshore geological storage, Energ. Environ. Sci. 2012, 5, 7132.

6. Jiaguo, Y.; Jingxiang, L.; Wei, X.; Peng, Z.; Mietek, J. Enhanced Photocatalytic $\mathrm{CO}_{2-}$ Reduction Activity of Anatase $\mathrm{TiO}_{2}$ by Co exposed $\{001\}$ and $\{101\}$ Facets, . Am. Chem. Soc. 2014, 136, 25, 8839-8842.

7. Xiang, Q.; Cheng, B.; Yu, J. Graphene-Based Photocatalysts for Solar-Fuel Generation, Angewandte Chemie Int.Ed. 2015, 54, 11350.

8. Kondratenko, E.V.; Guido, M.; Baltrusaitis, J.; Larrazábal, G.; Pérez-Ramírez, J. Status and perspectives of $\mathrm{CO}_{2}$ conversion into fuels and chemicals by catalytic, photocatalytic and electrocatalytic processes, J. Energ. Environ. Sci. 2013, 6, 3112.

9. $\mathrm{Fu}$, J., $\mathrm{Yu}$, J., Jiang, C., Cheng, B. g- $\mathrm{C}_{3} \mathrm{~N}_{4}$-based heterostructured photocatalysts, Adv. Energy Mater. 2018, 8 (3),1701503.

10. Wang, W.H.; Himeda, Y.; Muckerman, J.T.; Manbeck, G.F.; Fujita, E. $\mathrm{CO}_{2}$ hydrogenation to formate and methanol as an alternative to photo- and electrochemical $\mathrm{CO}_{2}$ reduction, Chem. Rev. 2015, 115, 12936-12973.

11. Low. J., Yu, J., Ho, W. Graphene-based photocatalysts for $\mathrm{CO}_{2}$ reduction to solar fuel, $J$. Phys. Chem. Lett. 2015, 6, 4244-4251.

12. Tu, W., Zhou, Y., Zou, Z. Photocatalytic conversion of $\mathrm{CO}_{2}$ into renewable hydrocarbon fuels: state-of-the-art accomplishment, challenges, and prospects, Adv. Mater. 2014, 26, $4607-4626$.

13. Jin, J., He, T. Facile synthesis of $\mathrm{Bi}_{2} \mathrm{~S}_{3}$ nanoribbons for photocatalytic reduction of $\mathrm{CO}_{2}$ into $\mathrm{CH}_{3} \mathrm{OH}$, Appl. Surf. Sci. 2017, 39, 364-370. 
14. Yu, W.; Chen, J., Shang, T., Chen, L., Gu, L., Peng, T. Direct Z-scheme g- $\mathrm{C}_{3} \mathrm{~N}_{4} / \mathrm{WO}_{3}$ photocatalyst with atomically defined junction for $\mathrm{H}_{2}$ production, Appl. Catal. B. 2017, 21, 693-704.

15. Di, T., Zhu, B., Cheng, B., Yu, J. Xu, J. A direct Z-scheme g- $\mathrm{C}_{3} \mathrm{~N}_{4} / \mathrm{SnS}_{2}$ photocatalyst with superior visible-light $\mathrm{CO}_{2}$ reduction performance, J. Catal. 2017, 352, 532-541.

16. Xinyong, T., Xiaorong, C., Yang, X., Hui, H., Yongping, G., Rui, W., Feng, C.; Wenkui, Z. Highly mesoporous carbon foams synthesized by a facile, cost-effective and template-free Pechini method for advanced lithium-sulfur batteries, J. Mater. Chem. A, 2013, 1, 3295.

17. Min, Y.; He, G; Xu, Q.; Chen, Y. Dual-functional $\mathrm{MoS}_{2}$ sheet-modified CdS branch-like heterostructures with increased photostability and photocatalytic activity, J Mater Chem A. 2014, 2, 2578-2584,.

18. Devi, S.; Korake, P; Achary, S.N.; Gupta, N.M. Genesis of increased photoactivity of $\mathrm{CdS} / \mathrm{Ni}_{\mathrm{x}}$ nanocomposites for visible-light-driven splitting of water, Int. J. Hydrogen Energy. 2014, 39, 19424-19433,.

19. Zhang, W; Xu, R. Surface engineered active photocatalysts without noble metals: CuSZnxCd1-xS nanospheres by one-step synthesis, Int. J. Hydrogen Energy. 2009, 34, 84958503.

20. Zong, X.; Han, J.; Ma, G.; Yan, H.; Wu, G.; Li, C. Photocatalytic $\mathrm{H}_{2}$ evolution on CdS loaded with $\mathrm{WS}_{2}$ as cocatalyst under visible light irradiation, J. Phys. Chem. C. 2011, 115, 12202-12208.

21. Eda, G.; Fanchini, G.; Chhowalla, M. Large-area ultrathin films of reduced graphene oxide as a transparent and flexible electronic material, Nat. Nanotechnol. 2008, 3, 270-274.

22. Stankovich, S.; Dikin, D.A.; Dommett, G.H.B.; Khlhaas, K.M.; Zimney, E.J.; Stach, E.A.; Piner, R.D.; Nguyen, S.T.; Ruoff, R.S. Graphene-based composite materials. Nature. 2006, $442,282-286$.

23. Tian, H.; Wan, C.; Xue, X.; Hu, X.; Wang, X. Effective Electron Transfer Pathway of the Ternary $\mathrm{TiO}_{2} / \mathrm{RGO} / \mathrm{Ag}$ Nanocomposite with Increased Photocatalytic Activity under Visible Light, Catalysts. 2017, 7, 156.

24. Tian, H.; Shen, K.; Hu, X.; Qiao, L.; Zheng, W.N. S co-doped graphene quantum dotsgraphene- $\mathrm{TiO}_{2}$ nanotubes composite with increased photocatalytic activity, J. Alloys Compd. 2017, 691, 369-377. 
25. Huang, H.; Liu, K.; Zhang, Y.; Chen, K.; Zhang, Y.; Tian, N. Tunable 3D hierarchical graphene-BiOI nanoarchitectures: Their in-situ preparation, and highly improved photocatalytic performance and photoelectrochemical properties under visible light irradiation, RSC Adv. 2014, 4, 49386-49394.

26. Rajendran, R.; Shrestha, L.K.; Minami, K.; Subramanian, M.; Jayavel, R.; Ariga, K. Dimensionally integrated nanoarchitectonics for a novel composite from 0D, 1D, and 2D nanomaterials: $\mathrm{RGO} / \mathrm{CNT} / \mathrm{CeO}_{2}$ ternary nanocomposites with electrochemical performance, J. Mater. Chem. A. 2014, 2, 18480-18487.

27. Yan, Y.; Sun, S.; Song, Y.; Yan, X.; Guan, W.; Liu, X.; Shi, W. Microwave-assisted in situ synthesis of reduced graphene oxide- $\mathrm{BiVO}_{4}$ composite photocatalysts and their increased photocatalytic performance for the degradation of ciprofloxacin, J. Hazard. Mater. 2013, $250,106-114$.

28. Stefan, D.; María del, C.A.; Elena, P.; Gonzalo, G. Electrochemical Reduction of Carbon Dioxide on Graphene-Based Catalysts, Molecules. 2021, $26(3), 572$.

29. Zambaga, O.; Kwang, Y.C.; Oh, W.C. Enhanced photocatalytic activity of $\mathrm{CO}_{2}$ reduction to methanol through the use of a novel-structured $\mathrm{CuCaAg} 2 \mathrm{Se}$-graphene- $\mathrm{TiO}_{2}$ ternary nanocomposite, New J. Chem., 2020,44, 16795-16809.

30. Oh, W.C.; Zhang, F.J. Preparation, and characterization of graphene oxide reduced from a mild chemical method, Asian J. Chem. 2011, 23, 875.

31. Zambaga, O.; Kwang, Y.C.; Oh, W.C, Novel Micro and Nanostructure of $\mathrm{AgCuInS}_{2-}$ Graphene- $\mathrm{TiO}_{2}$ Ternary Composite for Photocatalytic $\mathrm{CO}_{2}$ Reduction for Methanol Fuel, ACS Omega. 2020, 5, 26389-26401.

32. Ya-hui Y.; Ren-rui X.; Hang L.; Can-jun L.; Wen-hua L.; Fa-qi Z. Photoelectrocatalytic reduction of $\mathrm{CO}_{2}$ into formic acid using $\mathrm{WO}_{3-\mathrm{x}} / \mathrm{TiO}_{2}$ film as novel photoanode, Transactions of Nonferrous Metals Society of China. 2016, 26 (9), 2390-2396.

33. Ensafi, A.A.; Alinajafi, H.A.; Rezaei, B. Pt-modified nitrogen doped reduced graphene oxide: a powerful electrocatalyst for direct $\mathrm{CO}_{2}$ reduction to methanol. $J$ Electroanal Chem, 2016, 783, 82-89.

34. Xueqin, W.; Lasse, S.; Ren, S.; Stefan, W.; ,Peter, H.; Aref, M.; Chuanxu, Y.; Yudong, H.; Bo, B.I.; Flemming, B. The influence of crystallite size and crystallinity of anatase nanoparticles on the photo-degradation of phenol, J Catal, 2014, 310, 100-108.

35. Mathias, S.; Murilo, P.; Fernando, A.S.; Juliana M. de Souza e Silva, Italo O.M. Singular effect of crystallite size on the charge carrier generation and photocatalytic activity of nano$\mathrm{TiO}_{2}$, Appl. Surf. Sci. 2014, 319, 151-157. 
36. Malard, L.M.; Pimenta, M.A.; Dresselhaus, G.; .Dresselhaus, M.S. Raman spectroscopy in graphene, Phys. Rep. 2009, 473, 51-87.

37. Pandiaraman, M.; Soundararajan, N. Micro-Raman studies on thermally evaporated $\mathrm{Ag}_{2} \mathrm{Se}$ thin films, J. Theor. Appl. Phys. 2012, 6, 7.

38. Pierre, M.K.; Simon, D.; Malik, M.; Chuan, PL.; Mohamed, M.R.; Diaa, A.R.; Bonex, W.M. Strain and grain size of $\mathrm{TiO}_{2}$ nanoparticles from TEM, Raman spectroscopy and XRD: The revisiting of the Williamson-Hall plot method, Results Phys. 2018, 9, 628-635.

39. Mohammad, A.H.; Shahryar, M.; Nesa, E. The analysis of linear dose-responses in gammairradiated graphene oxide: Can FTIR analysis be considered a novel approach to examining the linear dose-responses in carbon nanostructures?, Radiat Phys Chem, 2020, 176, 109067.

40. Nguyen, T.T., Dang, L. M. Size Effect on the Structural and Magnetic Properties of Nanosized Perovskite $\mathrm{LaFeO}_{3}$ Prepared by Different Methods, Adv. Mater. Sci. Eng. 2012, 3803-3806.

41. Lei, G.; Changqing, Yi.; Yuanyuan, Luo.; Guotao, D. Facile Synthesis of the Composites of Polyaniline and $\mathrm{TiO}_{2}$ Nanoparticles Using Self-Assembly Method and Their Application in Gas Sensing, Nanomaterials, 2019, 9, 493.

42. Gondal, M.A.; Suliman, M.A.; Dastageer, M.A.; Gaik-Khuan, C.; Basheer, C.; Dan, Y.; Suwaiyan, A. Visible Light Photocatalytic Degradation of Herbicide (Atrazine) using Surface Plasmon Resonance Induced in Mesoporous AgWO $/$ SBA-15 Composite, J. Mol. Catal. A. Chem. 2016, 425, 208-216.

43. Hongliang, P.; Zaiyong, M.; Shijun, L.; Huagen, L.; Lijun, Y.; Fan, L.; Huiyu, S.; Yiliang, Z.; Bingqing, Z. High Performance Fe- and N- Doped Carbon Catalyst with Graphene Structure for Oxygen Reduction, Sci. Rep. 2013, 3(1).

44. Yang, G.; Liwei, M.; Wutao, W.; Shizhong, C.; Zhi, Z.; Hongwei, H.; Weihua, C. Double Metal Ions Synergistic Effect in Hierarchical Multiple Sulfide Microflowers for Increased Supercapacitor Performance, ACS Appl. Mater. Inter. 2015, 7 (7), 4311-4319.

45. Diptiman, D.; Md. Estak, A.; Sumit, M.; Biswajit, M.; Shyamal, K.S. Amorphous molybdenum sulfide quantum dots: an efficient hydrogen evolution electrocatalyst in neutral medium, J. Mater. Chem. A. 2016, 40, 15486-15493.

46. Demri, B.; Muster, D. XPS study of some calcium compounds, J. Mater. Process. Technol. 1995, 55, 311-314.

47. Pyrgiotakis, G.; Wolfgang, S.M. X-Ray Photoelectron Spectroscopy of Anatase- $\mathrm{TiO}_{2}$ Coated Carbon Nanotubes, Solid State Phenom. 2010, 162, 163-177. 


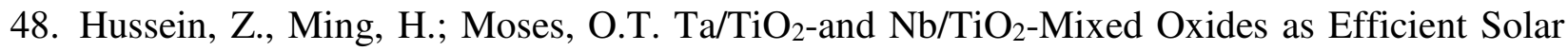
Photocatalysts: Preparation, Characterization, and Photocatalytic Activity, Int. J. Photoenergy. 2012, 1-9.

49. Zhou, X.; Sun, H.; Zhang, H.; Tu, W. One-pot hydrothermal synthesis of CdS/NiS photocatalyst for high $\mathrm{H}_{2}$ evolution from water under visible light, Int. J. Hydrogen Energy. 2017, 42, 11199-11205.

50. Kumar, S.; Bhunia, S.; Singh, J.; Ojha, A.K. Absence of room temperature ferromagnetism in $\mathrm{Fe}$ stabilized $\mathrm{ZrO}_{2}$ nanostructures and effect of $\mathrm{Fe}$ doping on its structural, optical and luminescence properties, J. Alloy. Compd. 2015, 649, 348-356.

51. Shuangfang, Z.; Xiaohong, Y.; Yinan, Z. Increased photocatalytic reduction of $\mathrm{CO}_{2}$ to methanol by $\mathrm{ZnO}$ nanoparticles deposited on ZnSe nanosheet, Chem. Phys. Lett. 2018, 693 $170-175$.

52. Adil, R.; Honglie, S.; Azhar, A.H.; Luanhong, S.; Rui, L.; Shusong, C. Studies of Z-scheme $\mathrm{WO}_{3}-\mathrm{TiO}_{2} / \mathrm{Cu}_{2} \mathrm{ZnSnS} 4$ ternary nanocomposite with enhanced $\mathrm{CO}_{2}$ photoreduction under visible light irradiation, J. $\mathrm{CO}_{2}$ Util. 2020, 37, 260-271.

53. Bingqing, W.; Yao, D.; Zirong, D.; Zhaohui, L. Rational design of ternary $\mathrm{NiS} / \mathrm{CQD} / \mathrm{ZnIn}_{2} \mathrm{~S}_{4}$ nanocomposites as efficient noble-metal-free photocatalyst for hydrogen evolution under visible light, Chinese Journal of Catalysis, 2019, 40 (3), 335-342.

54. O. Zambaga, W.C. Oh, Photocatalytic $\mathrm{CO}_{2}$ reduction with Graphene-based semiconductor, JMMP. 2019, 10, 127-140. 

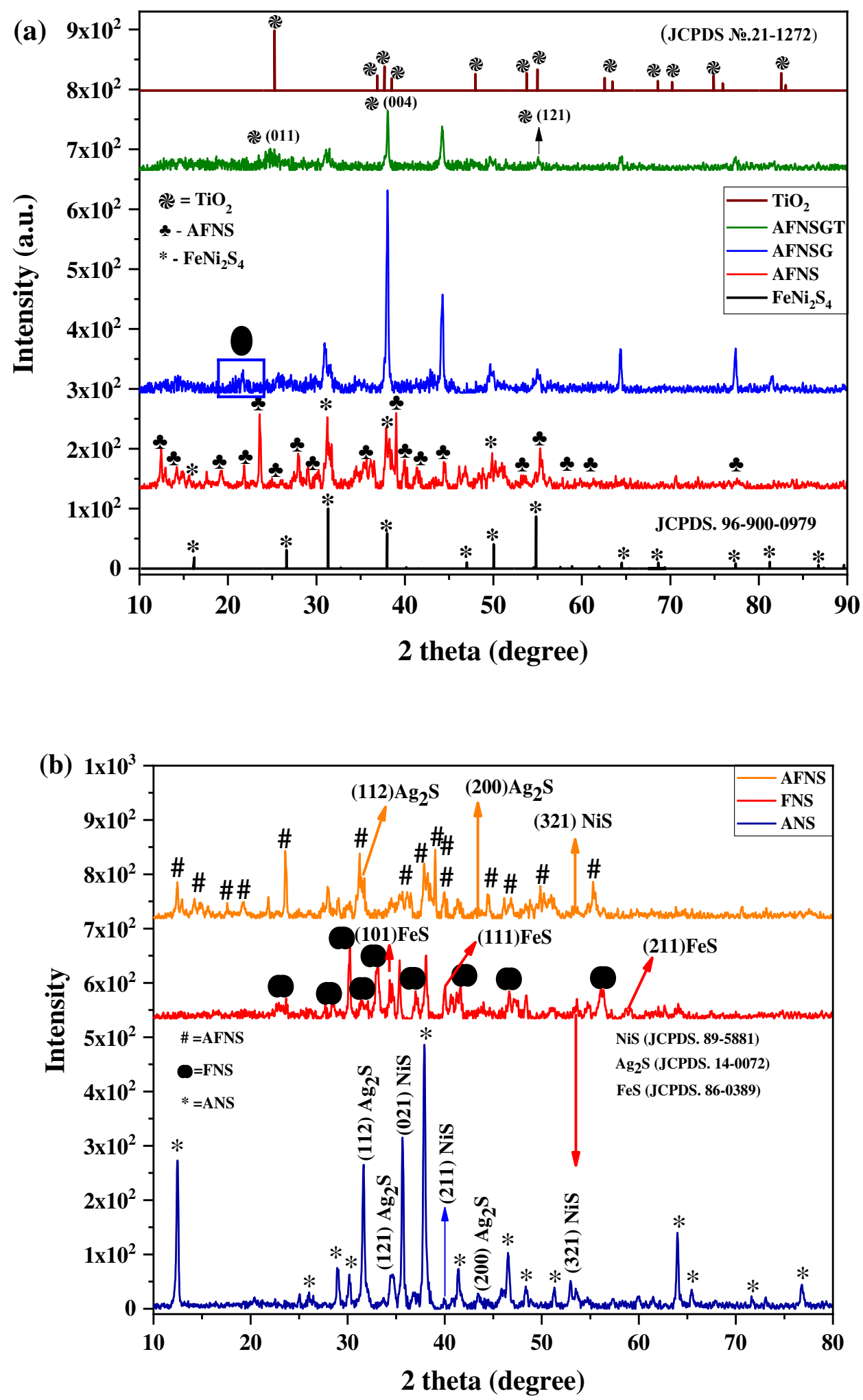


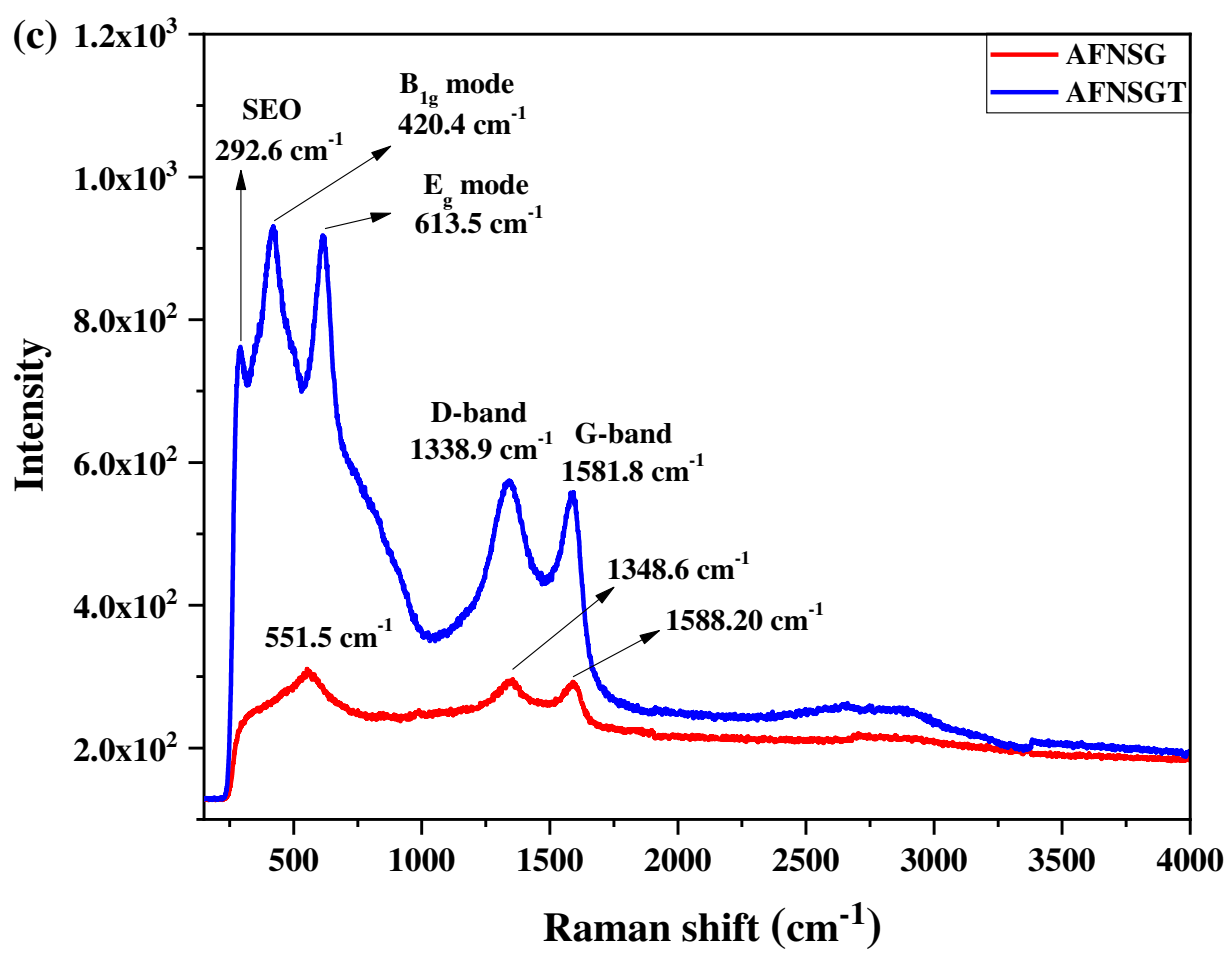

Figure 1. (a) XRD pattern of AFNS, AFNGS and AFNSGT, (b) $\mathrm{Ag}_{2} \mathrm{NiS}_{2}, \mathrm{FeNiS}_{2}$ and $\mathrm{AgFeNi} \mathrm{S}_{4}$ nanocomposite, (c) Raman spectra (followed by Pechini method). 

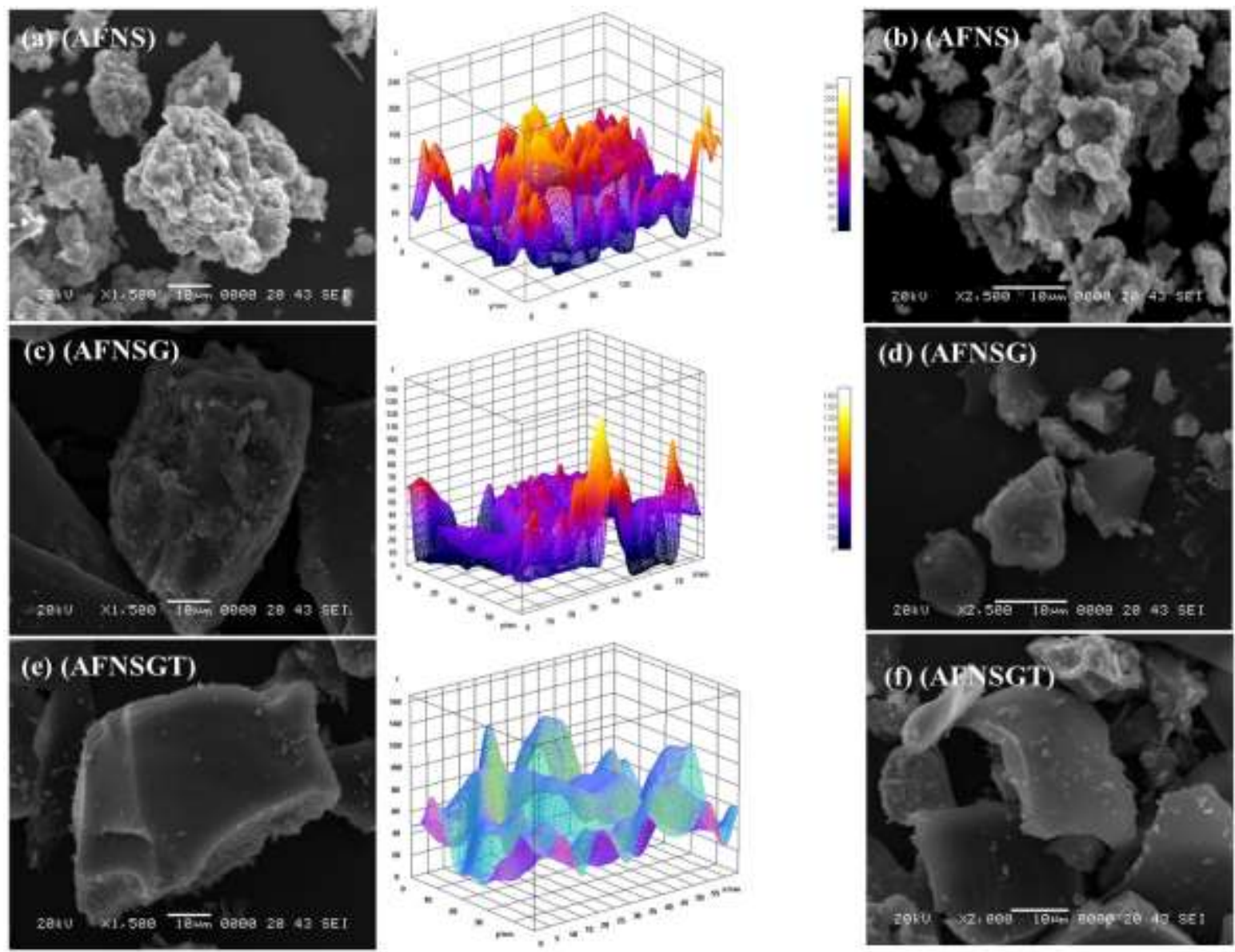

Figure 2. SEM image of (a-b) $\mathrm{AgFeNi}_{2} \mathrm{~S}_{4}$ quaternary nanocomposite, (c-d) $\mathrm{AgFeNi}_{2} \mathrm{~S}_{4}$ Graphene, (e-f) $\mathrm{AgFeNi}{ }_{2} \mathrm{~S}_{4}-\mathrm{Graphene}^{-\mathrm{TiO}_{2}}$ (followed by Pechini method). 

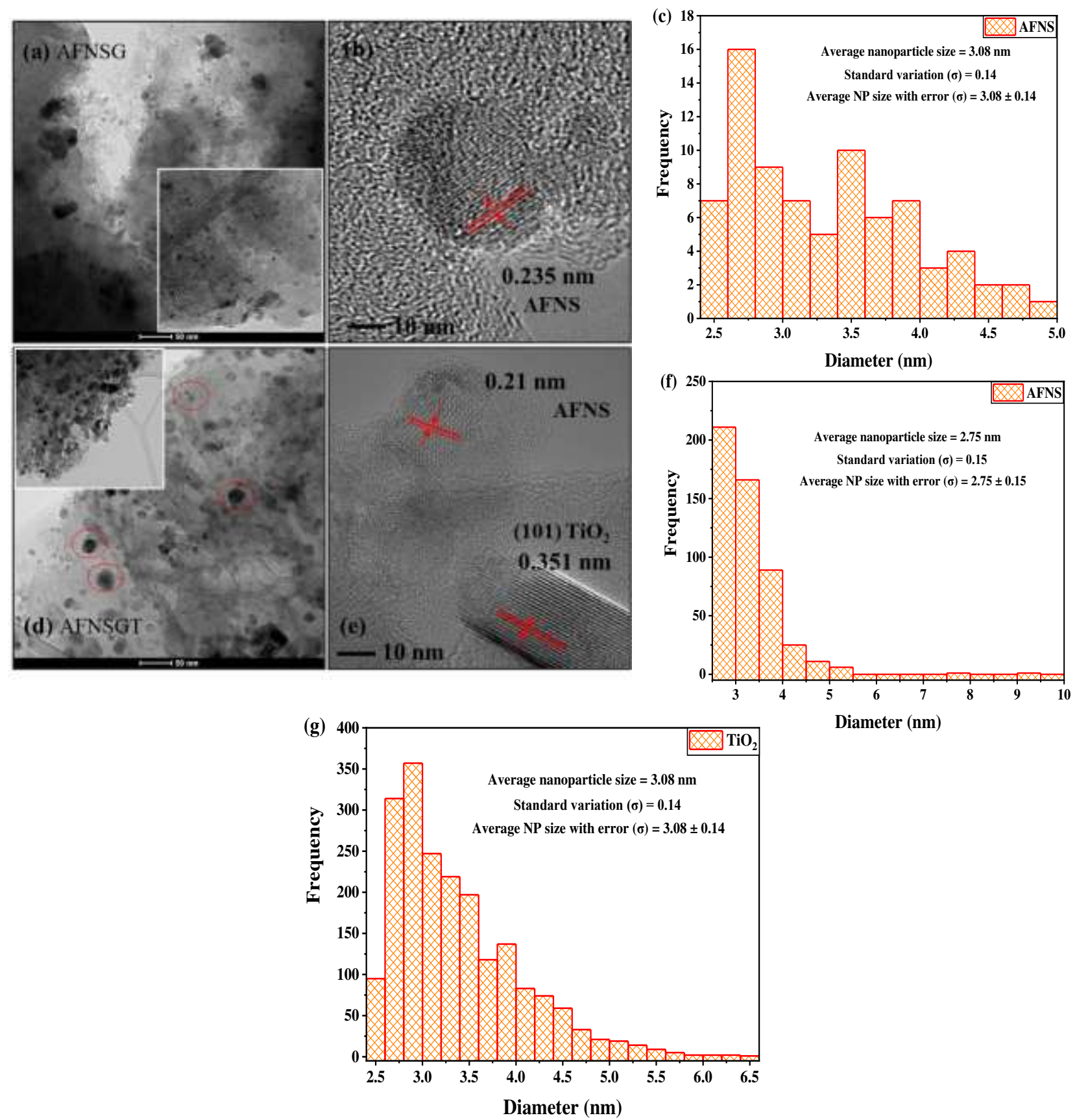

Figure 3. (a, d) TEM images, (b, e) HRTEM images of AFNSG and AFNSGT nanocomposite, (c, f, g) Nanoparticle size histogram of $\mathrm{AgFeNi}_{2} \mathrm{~S}_{4}, \mathrm{TiO}_{2}$ in binary and ternary nanocomposite (followed by Pechini method). 

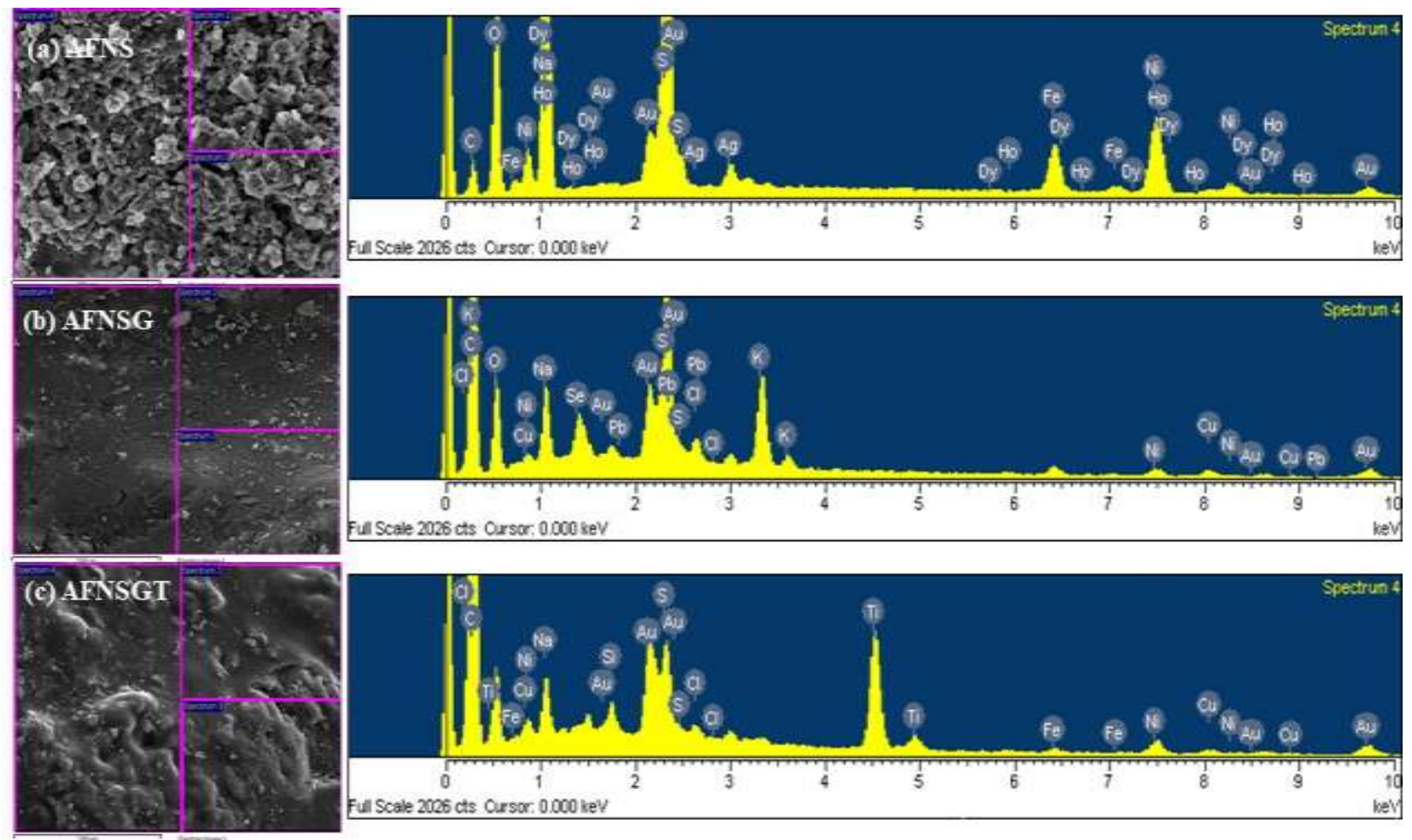

(AFNS) Element amount

(AFNSG) Element analysis
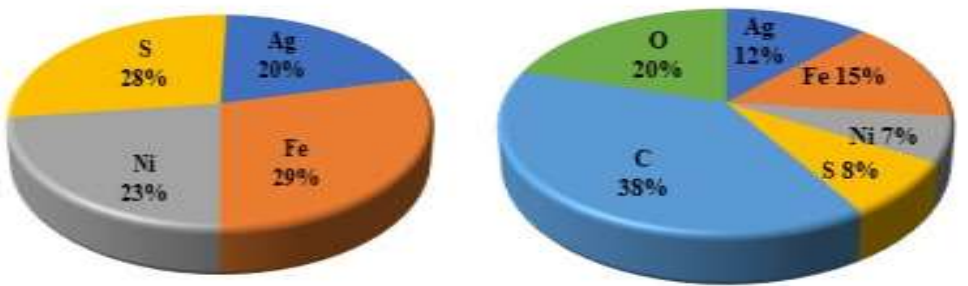

AFNSGT Element analysis

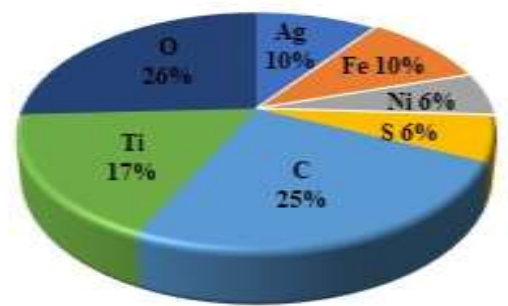

Figure 4. EDX spectrum of $\mathrm{AgFeNi}_{2} \mathrm{~S}_{4}$ quaternary nanocomposite, $\mathrm{AgFeNi} \mathrm{S}_{4}$-Graphene, $\mathrm{AgFeNi}_{2} \mathrm{~S}_{4}-\mathrm{Graphene}_{-} \mathrm{TiO}_{2}$ (followed by Pechini method). 


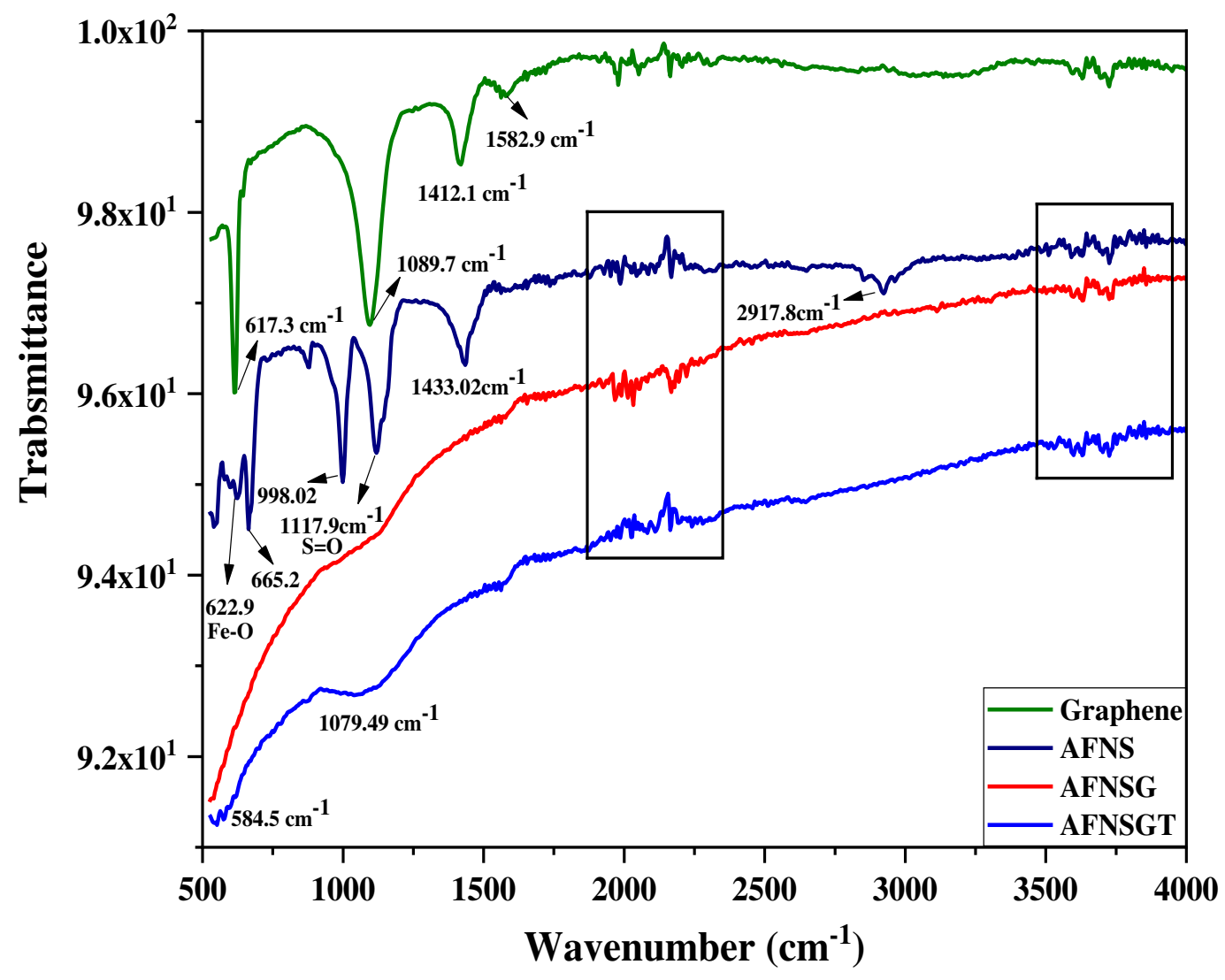

Figure 5. FTIR spectra of the samples. 


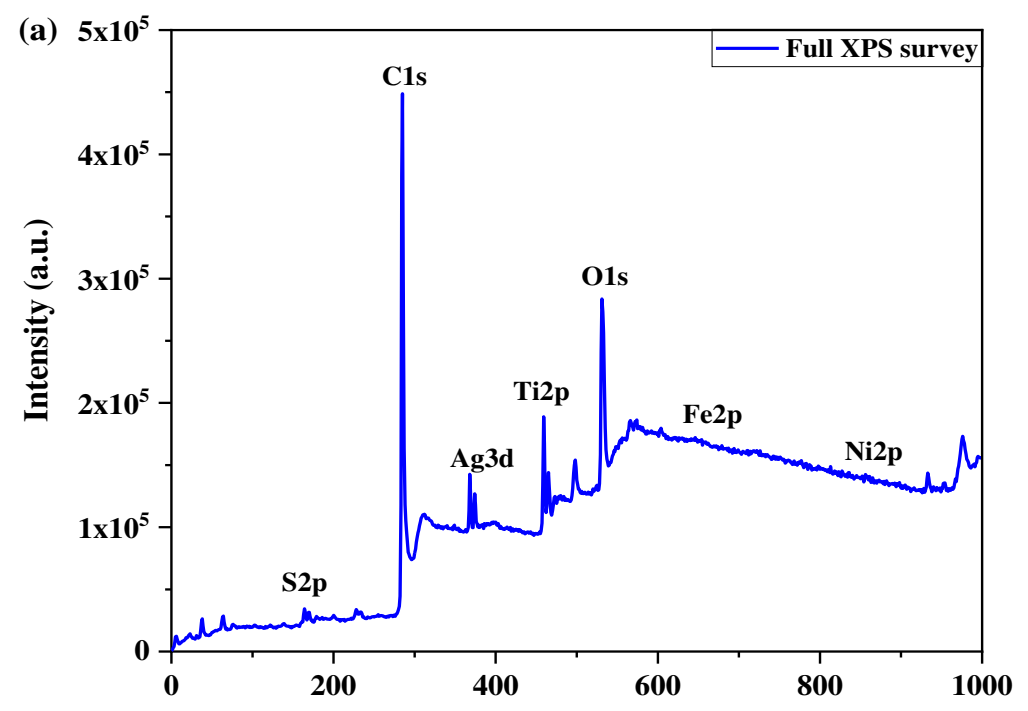

Binding energy (eV)
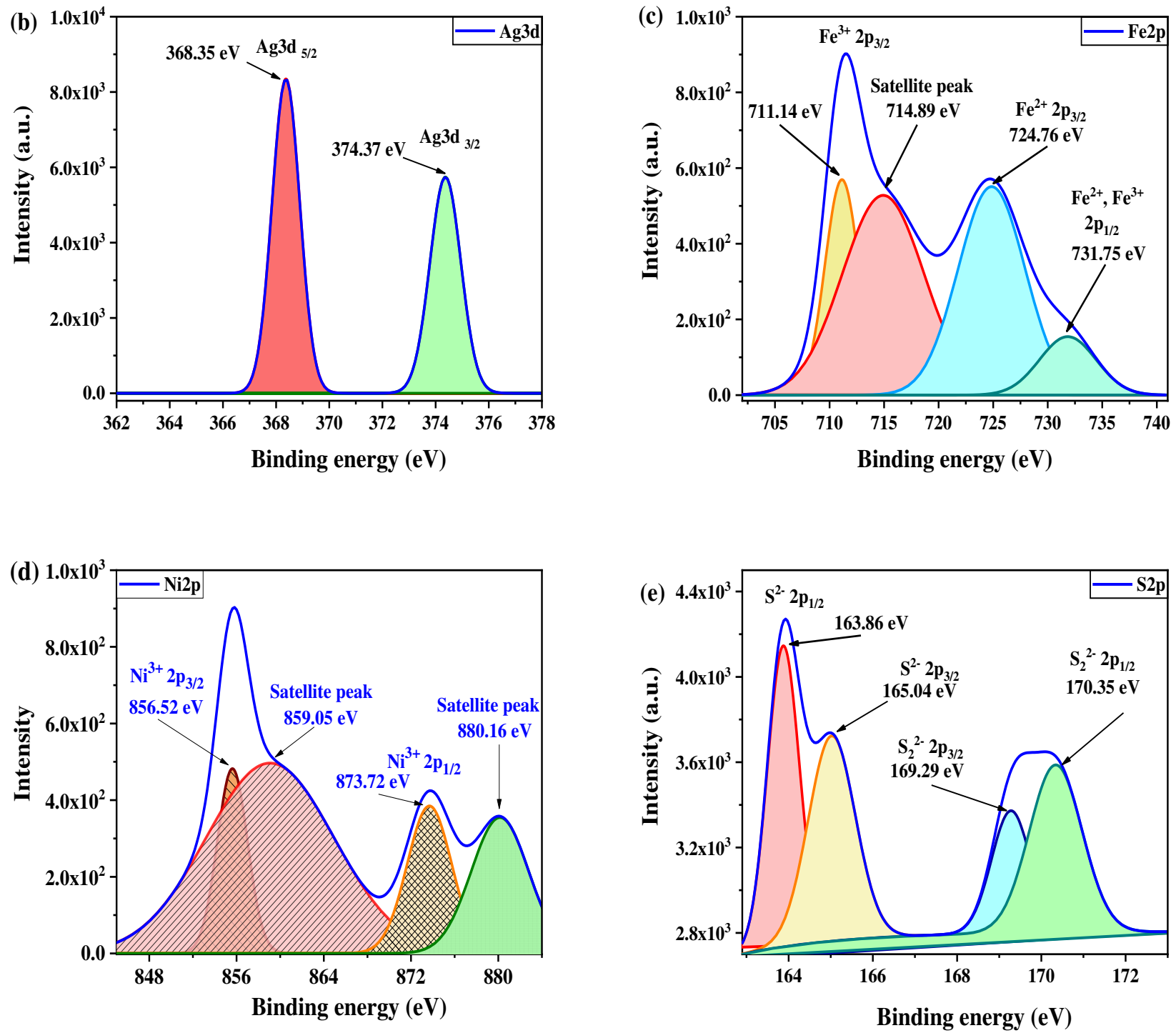

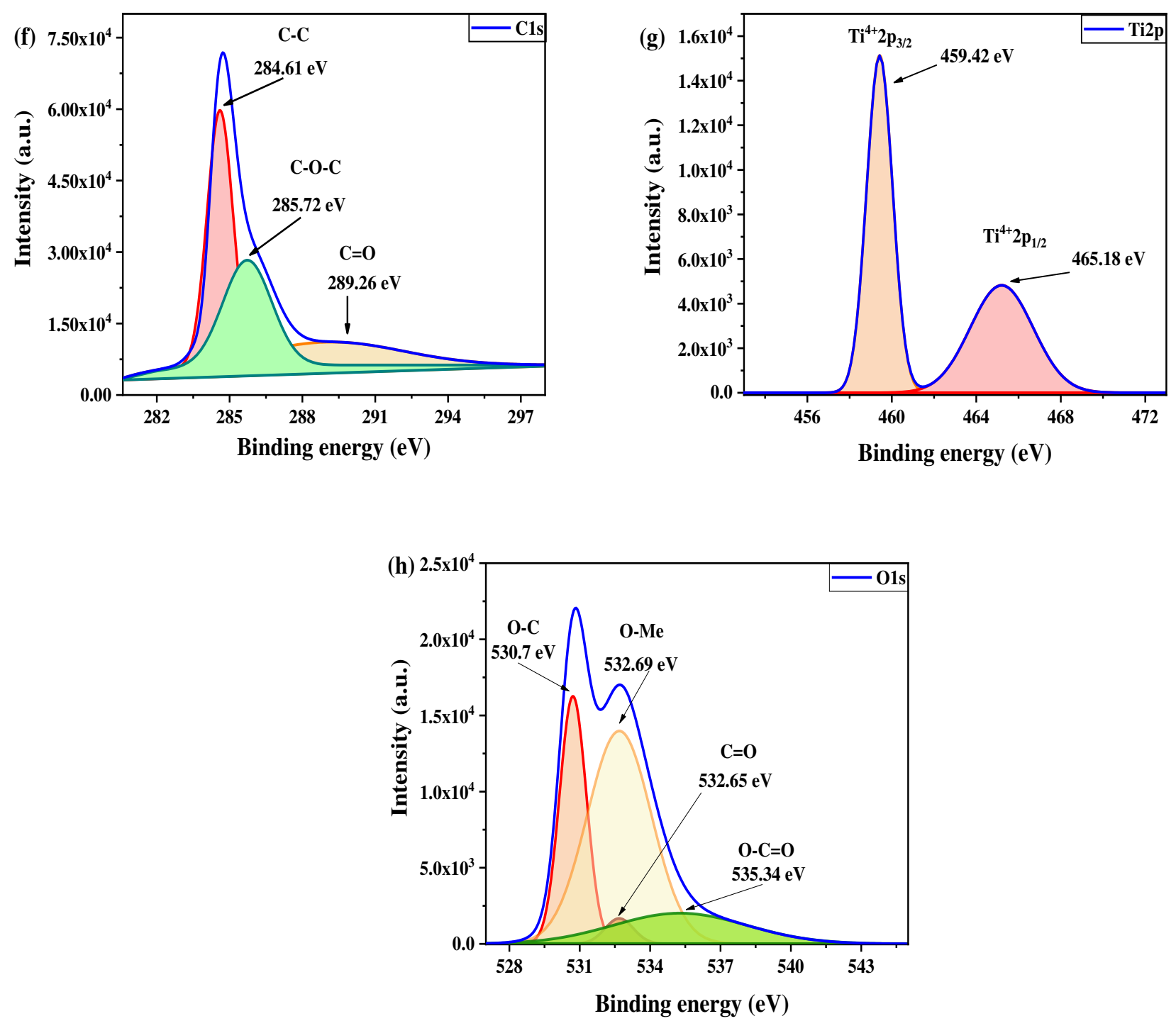

Figure 6. (a) XPS survey spectra and the high-resolution XPS spectra of $\mathrm{AgFeNi}_{2} \mathrm{~S}_{4-}$

Graphene- $\mathrm{TiO}_{2}$ (synthesized by Pechini method), (b) Ag3d, (c) Fe2p, (d) Ni2p, (e) S2p, (f) C1s, (g) Ti2p and (h) O1s. 

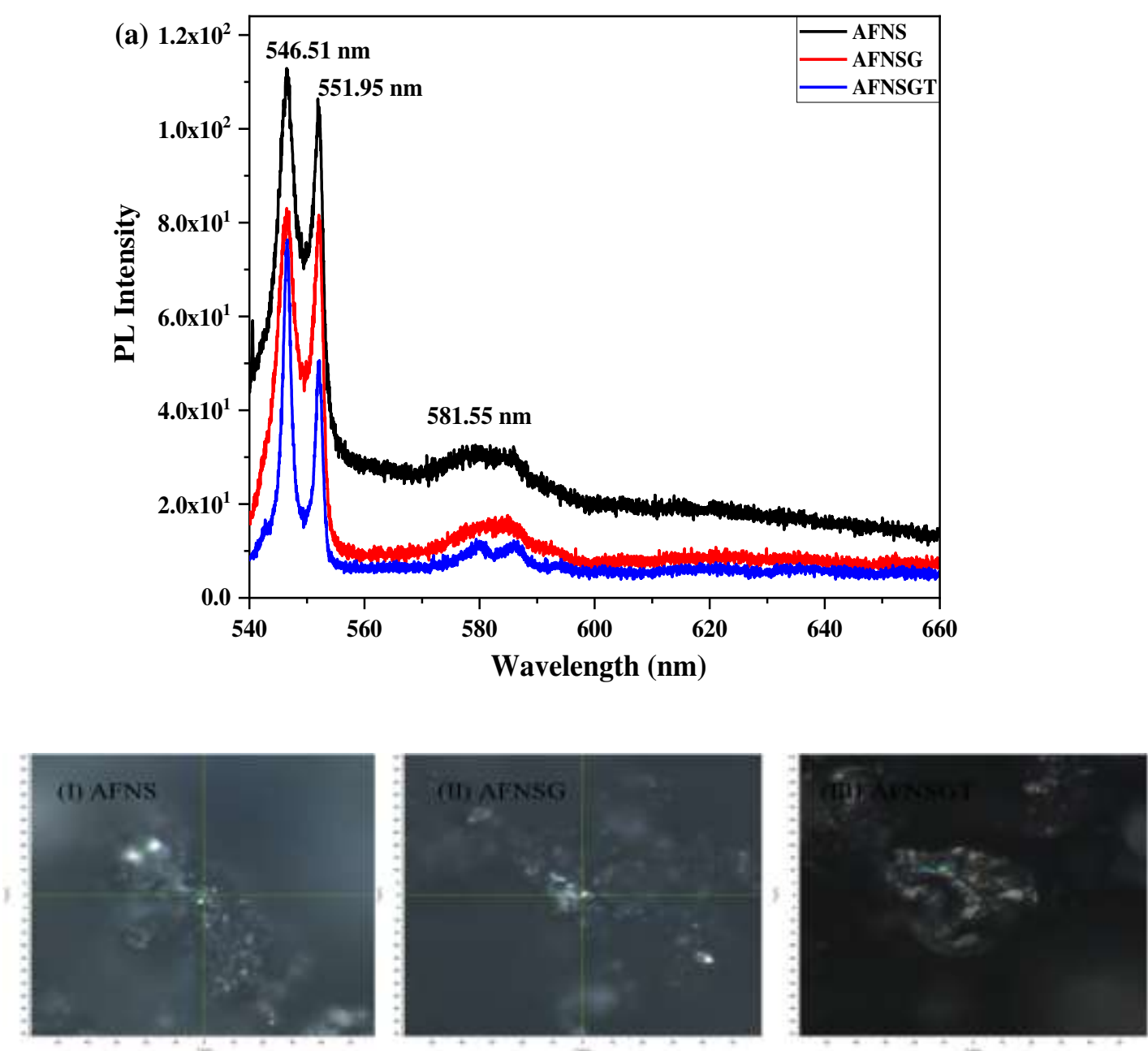

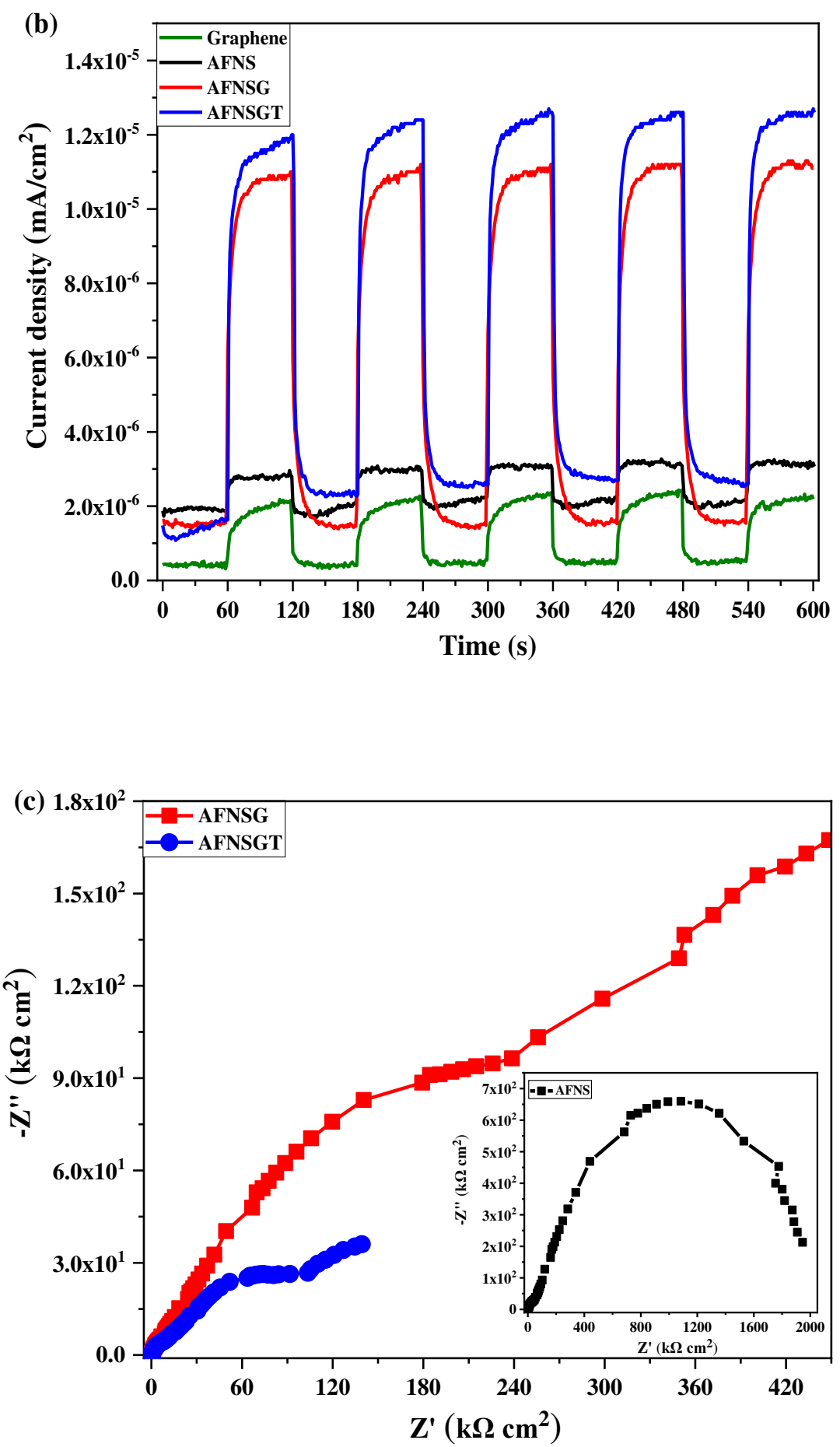

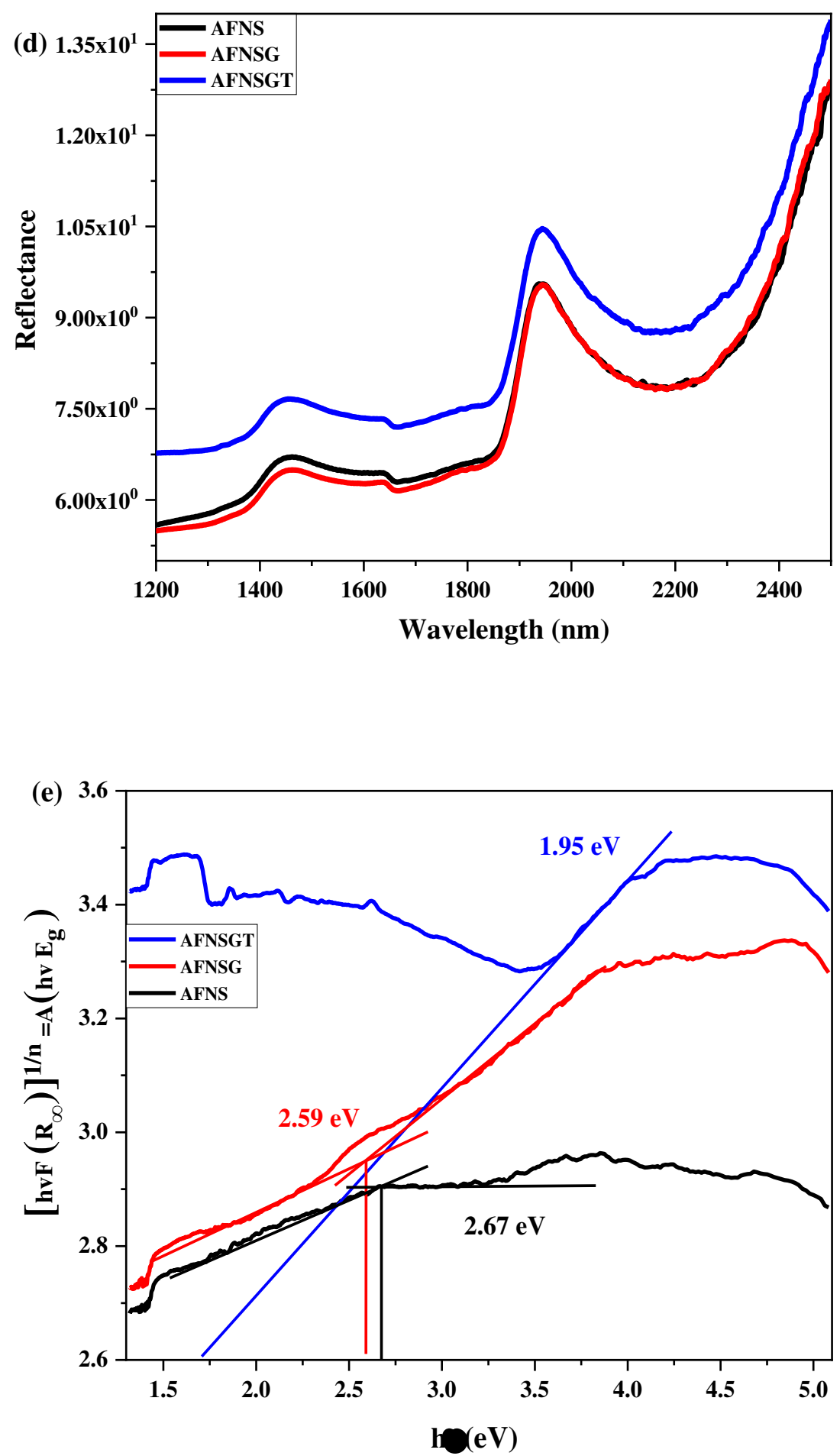

Figure 7. (a) Photoluminescence spectra, (b) Photocurrent response, (c) Nyquist plot, (d) reflectance spectra and (e) DRS of $\mathrm{AgFeNi}_{2} \mathrm{~S}_{4}, \mathrm{AgFeNi}_{2} \mathrm{~S}_{4}-\mathrm{Graphene}$ and $\mathrm{AgFeNi}_{2} \mathrm{~S}_{4}$ Graphene- $\mathrm{TiO}_{2}$ (followed by Pechini method). 

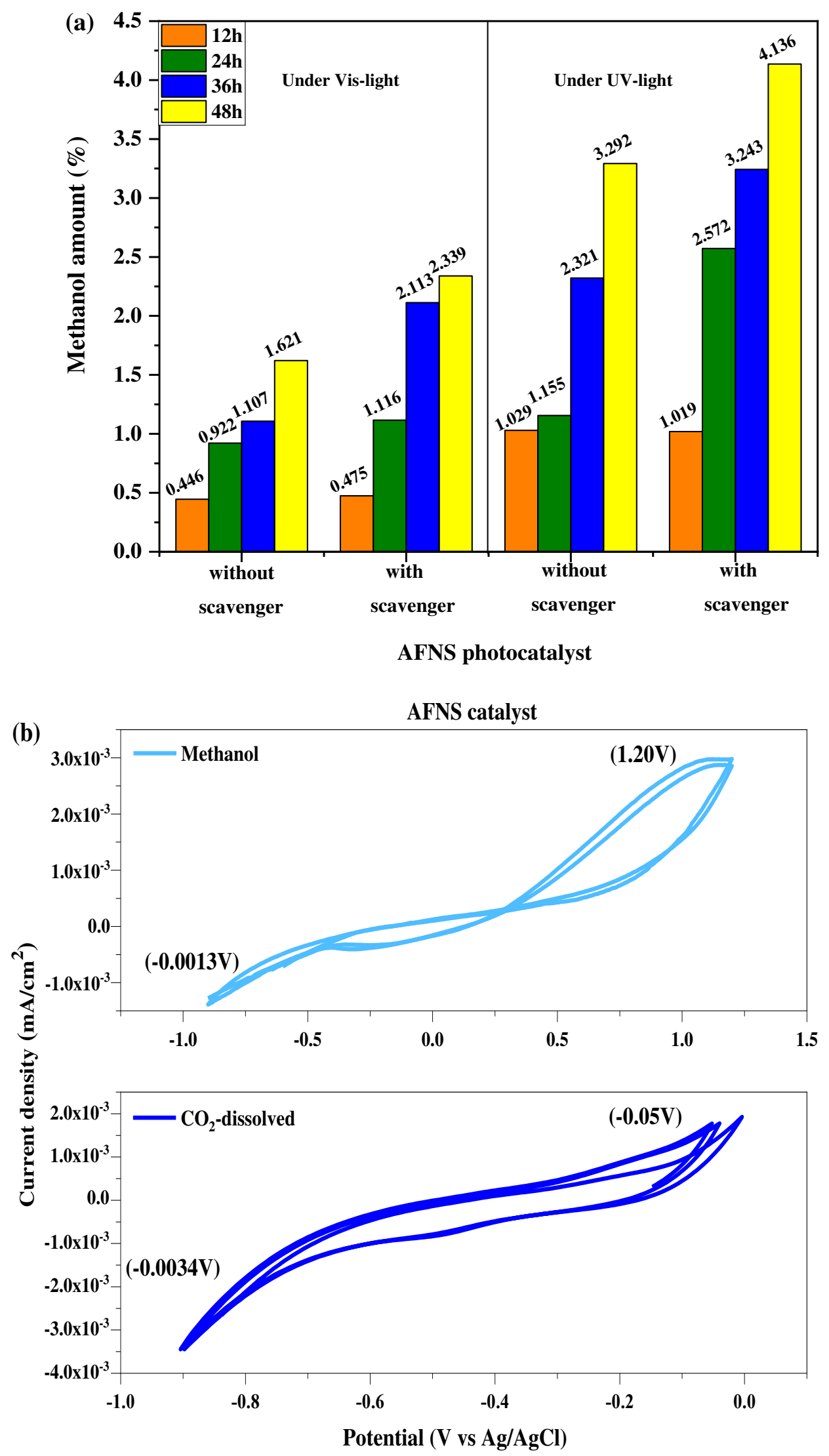


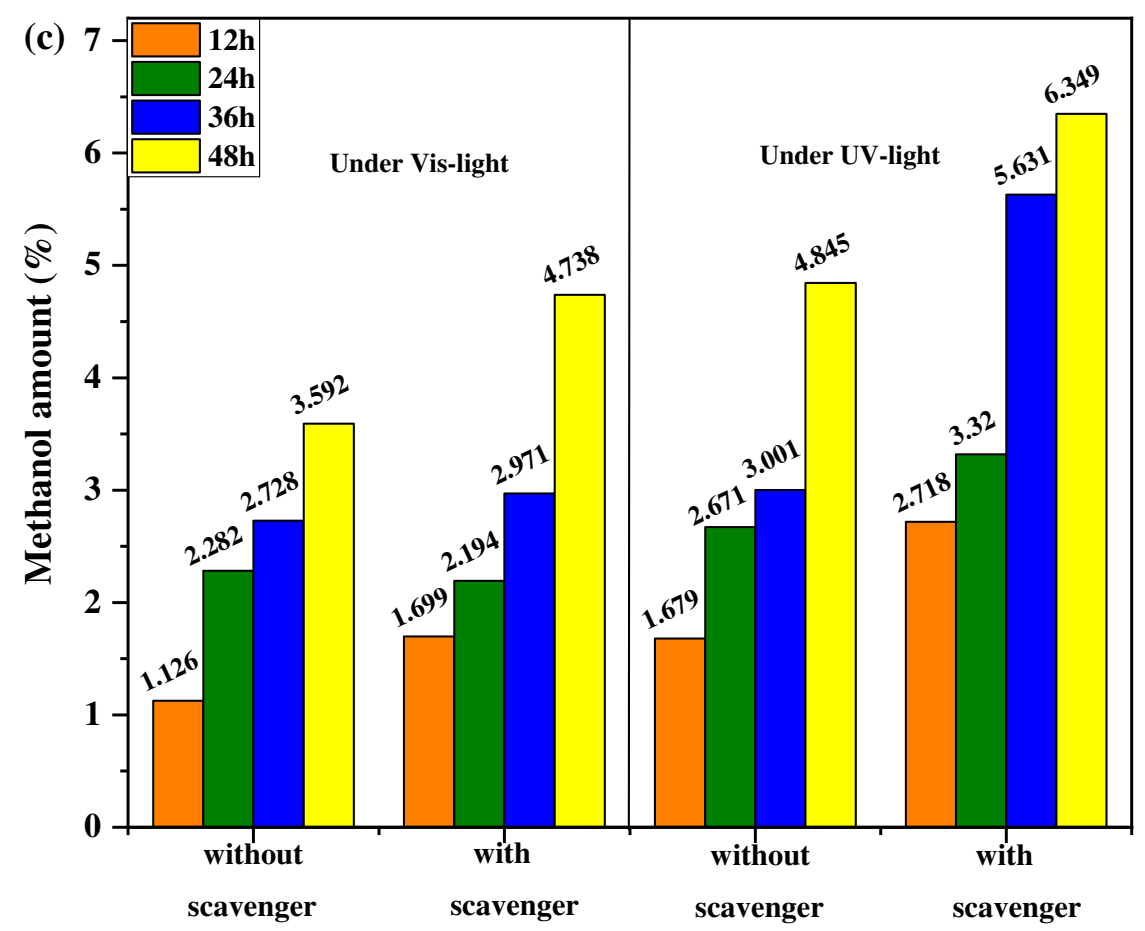

AFNSG photocatalyst

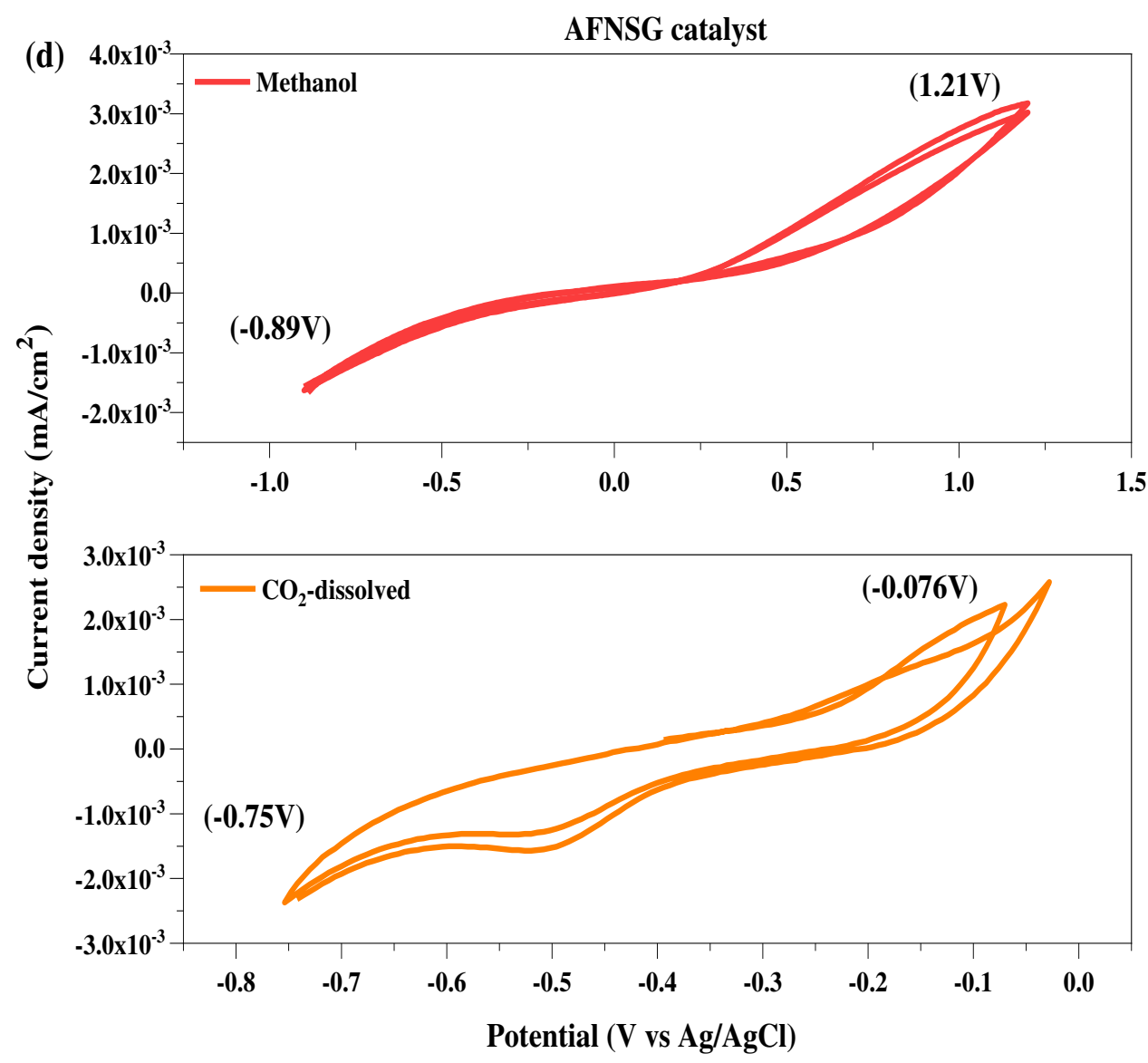




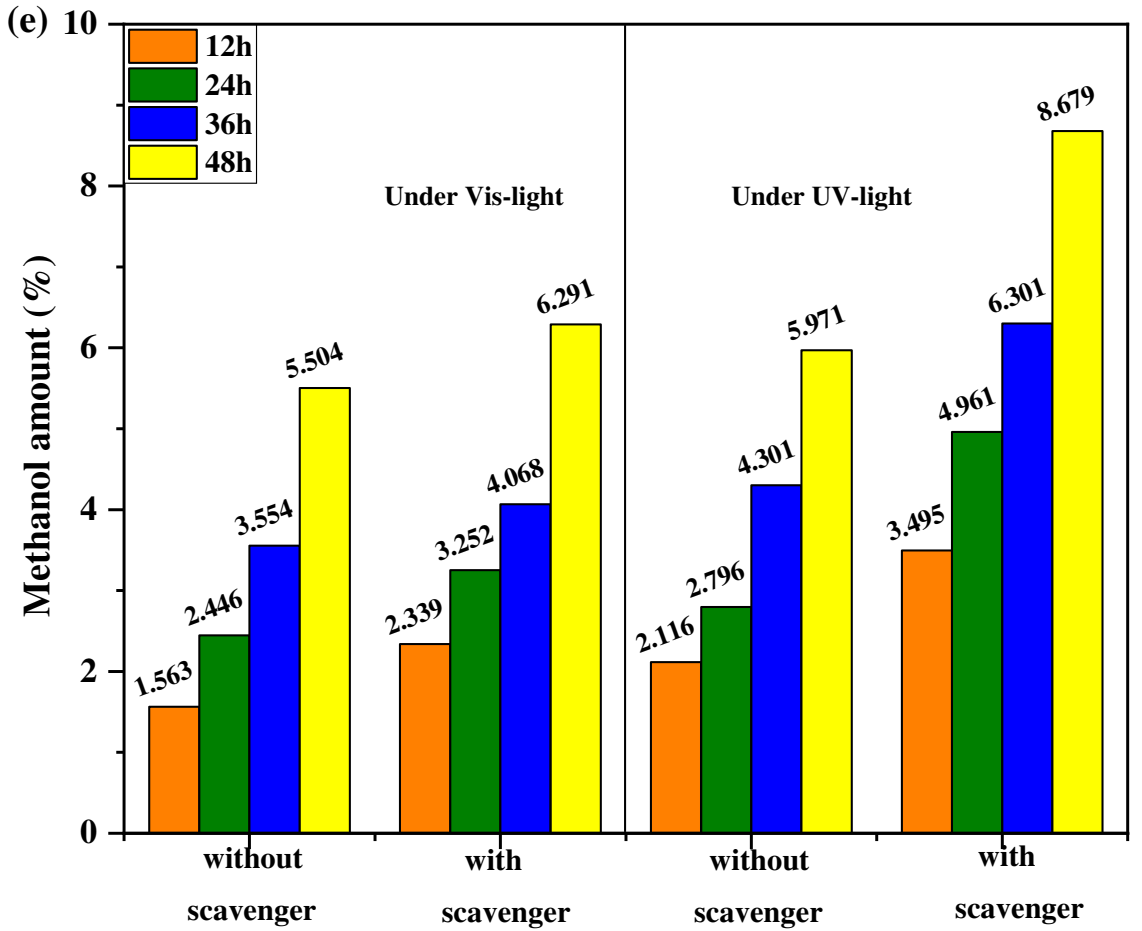

AFNSGT photocatalyst
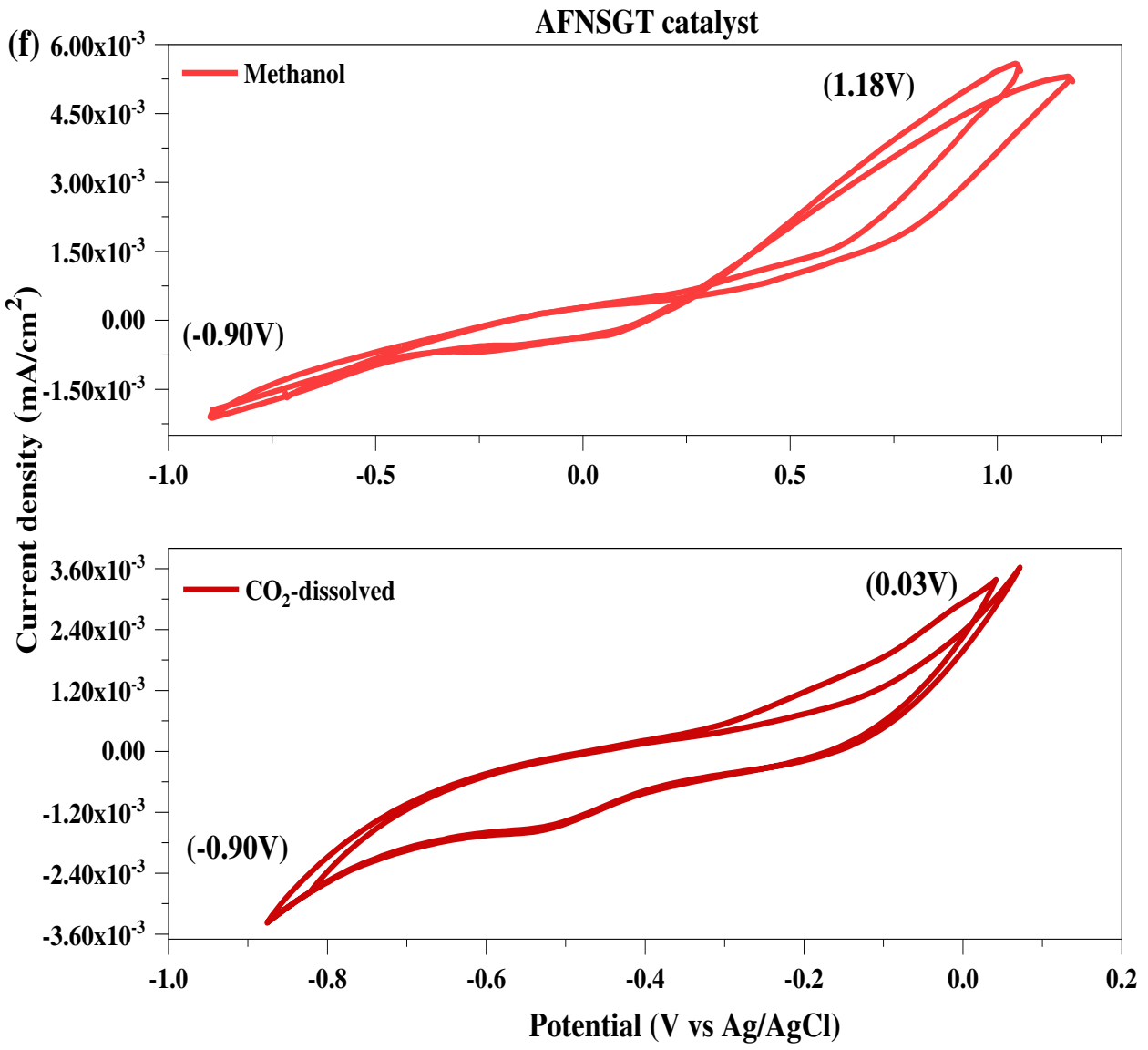
Figure 8. Quantitative analysis of Alcohol result over unary, binary and ternary nanocomposite : effect of scavenger and light irradiation, Cyclic voltammetry test of the AFNS, AFNSG and AFNSGT in $\mathrm{CO}_{2}$ dissolved and after the $\mathrm{CO}_{2}$ electrolysis $(-1.2 \mathrm{~V}$ to $1.5 \mathrm{~V}$ vs $\mathrm{Ag} / \mathrm{AgCl})$ under 100 $\mathrm{mV} \mathrm{s}^{-1}$ scan rate.

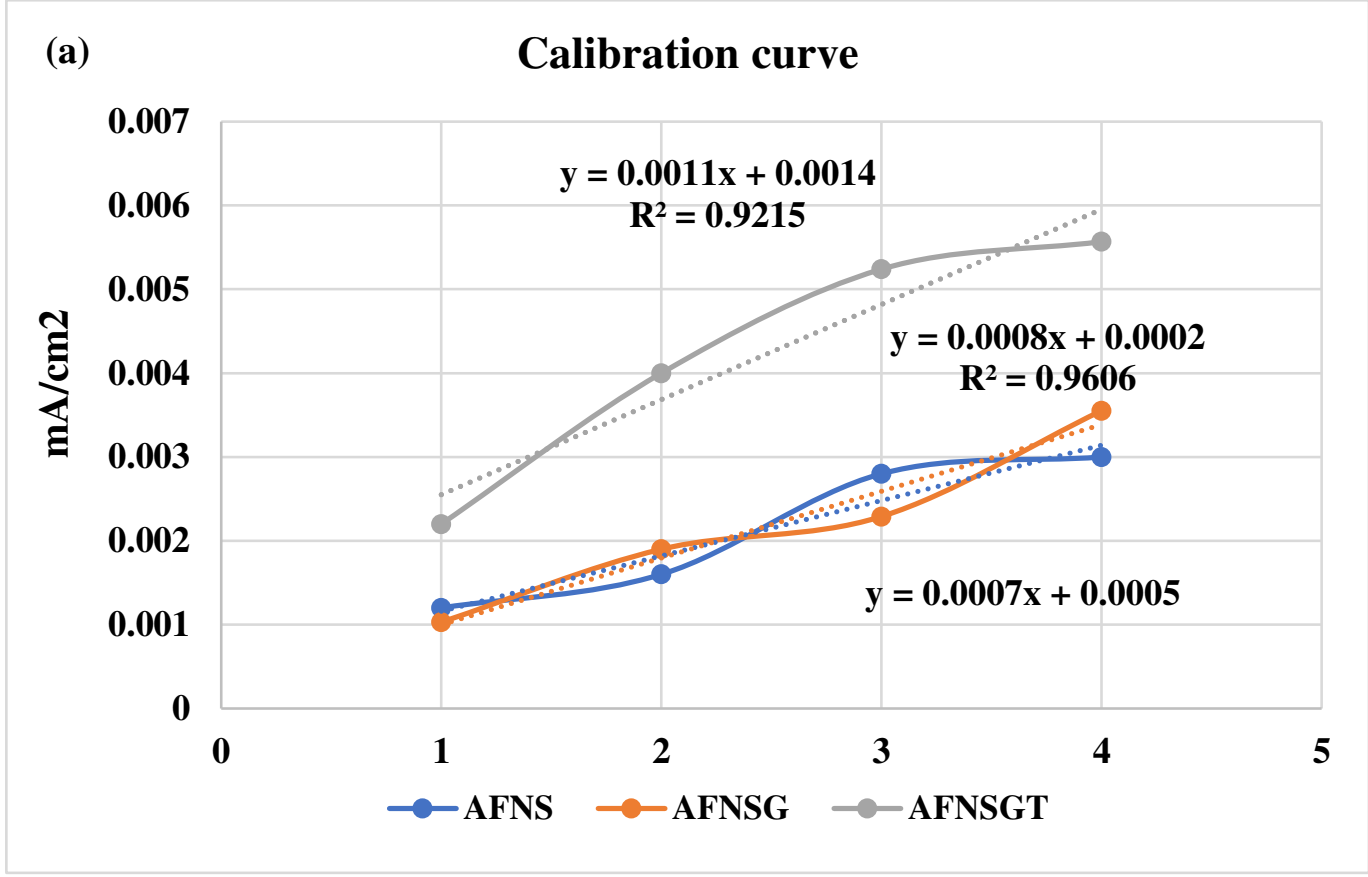

(b)

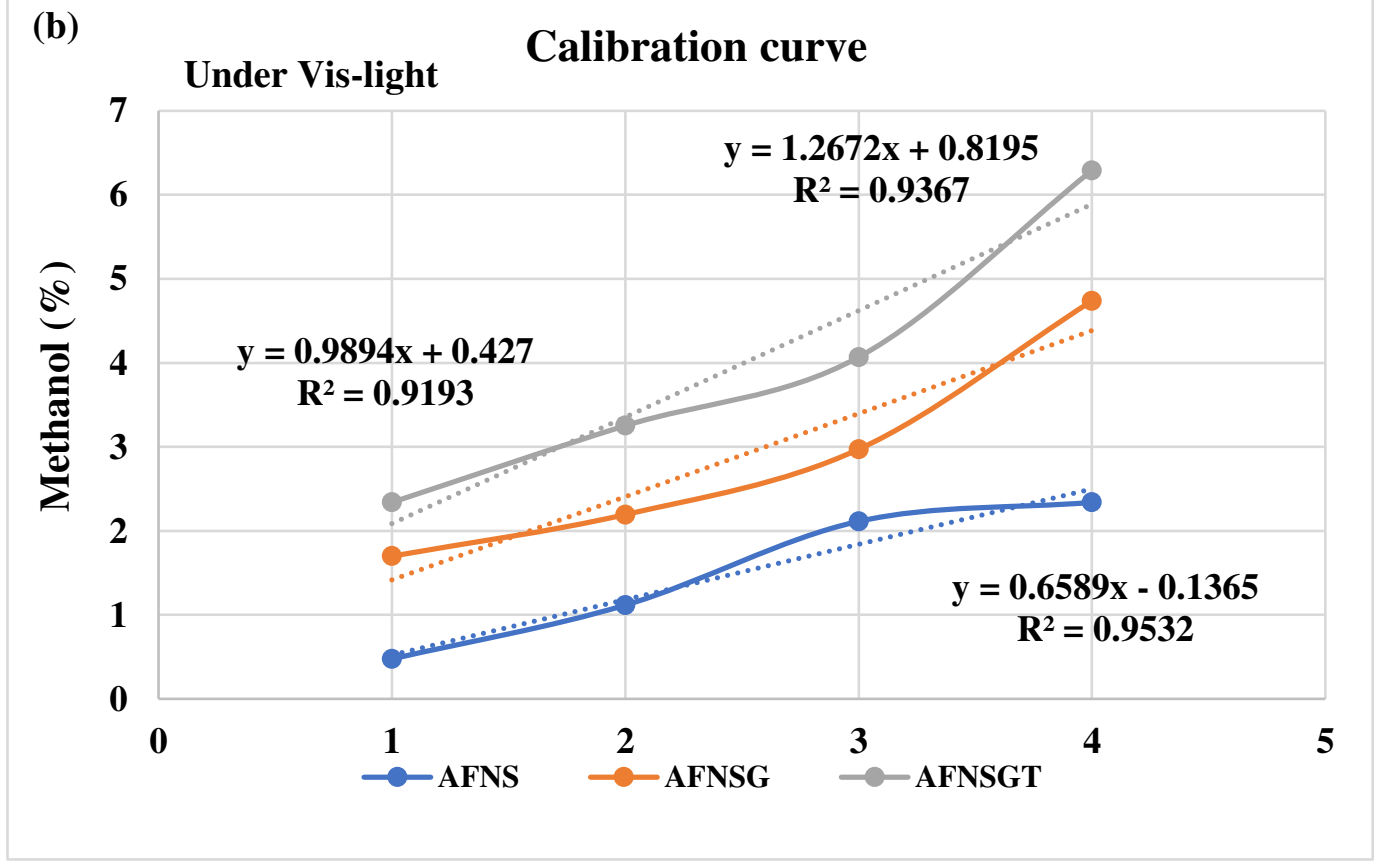




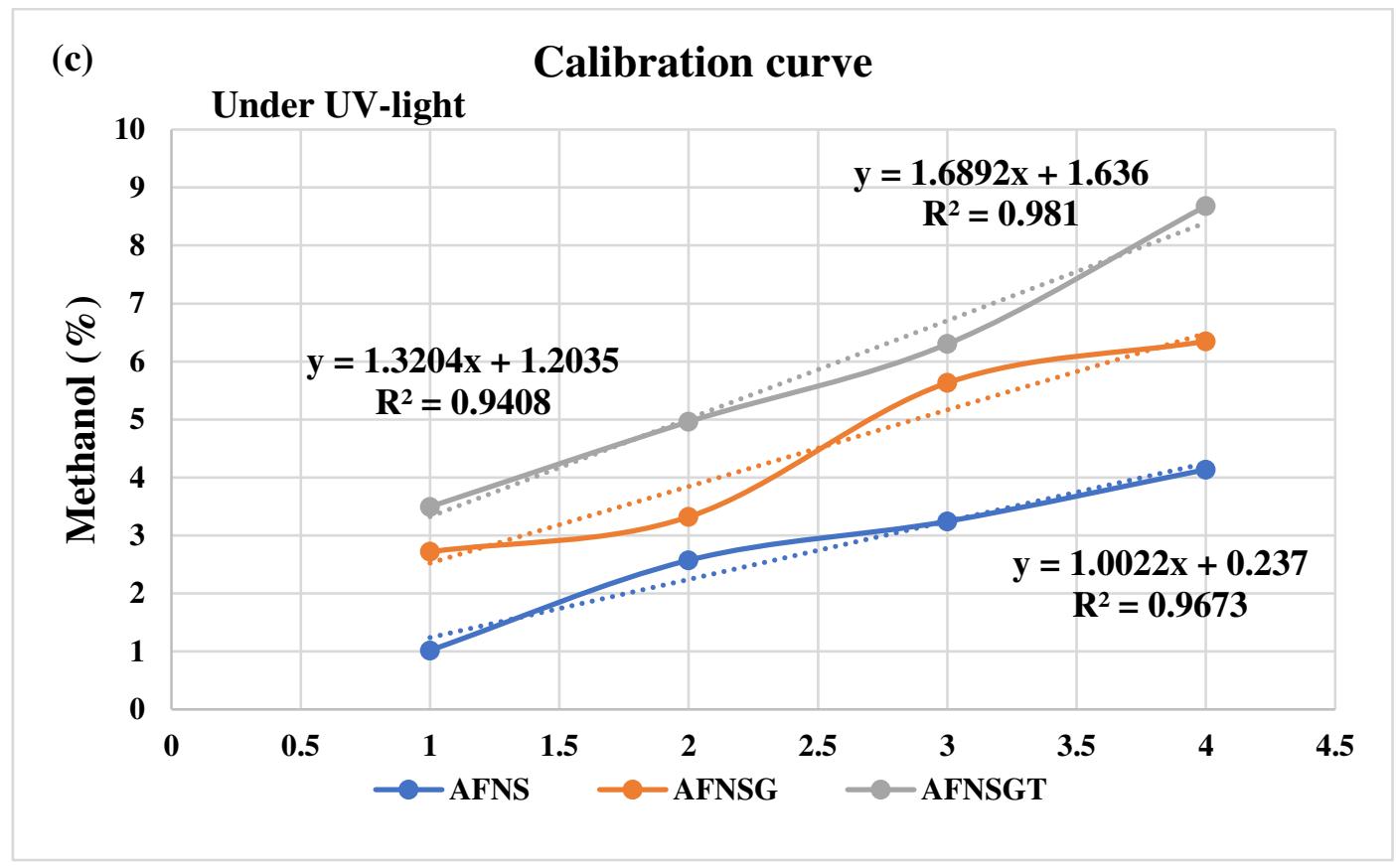

Figure 9. Calibration curve produced by the electrochemical and photocatalytic $\mathrm{CO}_{2}$ reduction over AFNS, AFNSG and AFNSGT.

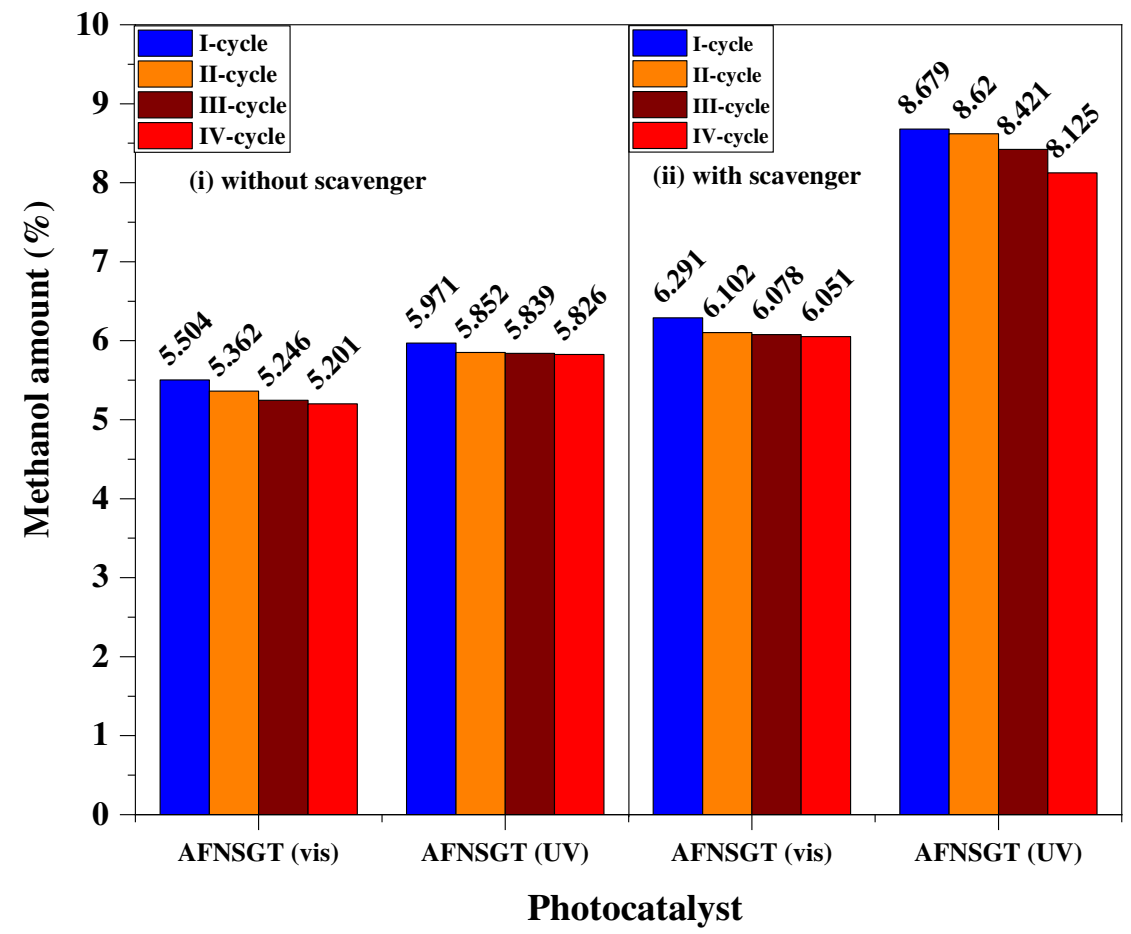

Figure 9. Stability analysis of $\mathrm{AgFeNi}_{2} \mathrm{~S}_{4}-\mathrm{Graphene} \mathrm{TiO}_{2}$ in multiple cycles (i) without scavenger, (ii) with $(0.3 \mathrm{~g})$ scavenger. 


\section{Supplementary Files}

This is a list of supplementary files associated with this preprint. Click to download.

- Supplementaryfile210610.docx 